\title{
Characterization of nucleic acids from extracellular vesicle-enriched human sweat
}

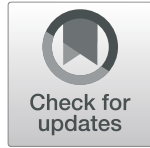

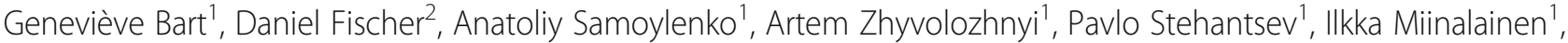 \\ Mika Kaakinen', Tuomas Nurmi ${ }^{1}$, Prateek Singh ${ }^{1,3}$, Susanna Kosamo ${ }^{1}$, Lauri Rannaste ${ }^{4}$, Sirja Viitala²,
}

Jussi Hiltunen ${ }^{4}$ and Seppo J Vainio ${ }^{1 *}$

\begin{abstract}
Background: The human sweat is a mixture of secretions from three types of glands: eccrine, apocrine, and sebaceous. Eccrine glands open directly on the skin surface and produce high amounts of water-based fluid in response to heat, emotion, and physical activity, whereas the other glands produce oily fluids and waxy sebum. While most body fluids have been shown to contain nucleic acids, both as ribonucleoprotein complexes and associated with extracellular vesicles (EVs), these have not been investigated in sweat. In this study we aimed to explore and characterize the nucleic acids associated with sweat particles.

Results: We used next generation sequencing (NGS) to characterize DNA and RNA in pooled and individual samples of EV-enriched sweat collected from volunteers performing rigorous exercise. In all sequenced samples, we identified DNA originating from all human chromosomes, but only the mitochondrial chromosome was highly represented with $100 \%$ coverage. Most of the DNA mapped to unannotated regions of the human genome with some regions highly represented in all samples. Approximately $5 \%$ of the reads were found to map to other genomes: including bacteria (83\%), archaea (3\%), and virus (13\%), identified bacteria species were consistent with those commonly colonizing the human upper body and arm skin. Small RNA-seq from EV-enriched pooled sweat RNA resulted in $74 \%$ of the trimmed reads mapped to the human genome, with $29 \%$ corresponding to unannotated regions. Over $70 \%$ of the RNA reads mapping to an annotated region were tRNA, while misc. RNA (18, $5 \%)$, protein coding RNA (5\%) and miRNA (1,85\%) were much less represented. RNA-seq from individually processed EV-enriched sweat collection generally resulted in fewer percentage of reads mapping to the human genome (7$45 \%$ ), with $50-60 \%$ of those reads mapping to unannotated region of the genome and $30-55 \%$ being tRNAs, and lower percentage of reads being rRNA, LincRNA, misc. RNA, and protein coding RNA.
\end{abstract}

Conclusions: Our data demonstrates that sweat, as all other body fluids, contains a wealth of nucleic acids, including DNA and RNA of human and microbial origin, opening a possibility to investigate sweat as a source for biomarkers for specific health parameters.

Keywords: Extracellular vesicles (EV), Sweat, Genomics, Transcriptomics, Exercise, Microbiome, Metagenomics, Skin

\footnotetext{
*Correspondence: seppo.vainio@oulu.fi

${ }^{1}$ Faculty of Biochemistry and Molecular Medicine, Disease Networks Research Unit, Laboratory of Developmental Biology, Kvantum Institute, Infotech Oulu, University of Oulu, 90014 University of Oulu, Oulu, Finland

Full list of author information is available at the end of the article
}

(c) The Author(s). 2021 Open Access This article is licensed under a Creative Commons Attribution 4.0 International License, which permits use, sharing, adaptation, distribution and reproduction in any medium or format, as long as you give appropriate credit to the original author(s) and the source, provide a link to the Creative Commons licence, and indicate if changes were made. The images or other third party material in this article are included in the article's Creative Commons licence, unless indicated otherwise in a credit line to the material. If material is not included in the article's Creative Commons licence and your intended use is not permitted by statutory regulation or exceeds the permitted use, you will need to obtain permission directly from the copyright holder. To view a copy of this licence, visit http://creativecommons.org/licenses/by/4.0/ The Creative Commons Public Domain Dedication waiver (http://creativecommons.org/publicdomain/zero/1.0/) applies to the data made available in this article, unless otherwise stated in a credit line to the data. 


\section{Background}

Sweat is a biofluid continuously produced by skin glands for secretion to the body surface. Unlike urine, which accumulates in the bladder over time, and is flushed out only when the bladder is emptied, sweat is released continuously, from less than $1 \mathrm{pL} /$ minute in resting conditions to several $\mathrm{nL} /$ minute per gland during exercise [1], and could therefore be collected non-invasively for analysis. In addition to changes in the sweat release rate, the composition of sweat is altered by physical activity and presence of health conditions. Detection of specific metabolites, ions, hormones, peptides, cytokines, and glucose in sweat has potential diagnostic value. Glucose levels in sweat reflect changes in the blood glucose level, and this observation has led to development of noninvasive glucose monitoring methods [2-4]. The sweat proteome has been shown to be different between healthy subjects and people with schizophrenia [5], and between healthy people and patients with active tuberculosis [6]. The presence of viral particles in sweat has also been reported, consisting mostly in infectious viruses such as papilloma or polyoma virus and bacteriophages [7], but other infective viruses like Hepatitis $C$ virus have also been detected [8]. Sweat analysis for forensic purposes has also been reported $[9,10]$, but while saliva is routinely used for genotyping, no genetic tests based on sweat nucleic acids have been published beyond finding specific markers to distinguish sweat from other biofluids [11].

In addition to ions and macromolecules, biofluids carry insoluble particles containing nucleic acids, including lipid droplets [12], ribonucleoprotein complexes, extracellular vesicles (EVs) and whole cells. Systematic studies of sweat EV cargo are difficult, because of the mixtures of environmental contaminants on the skin surface, and because most of the collection methods interfere with the normal sweating process [13]. Sweat contains several types of EVs: apoptotic bodies from holocrine secretion of sebaceous glands [14], large membrane vesicles from axillary apocrine glands [15], and 100-200 nm EVs with CD63, CD9 and CD81 tetraspanins $[16,17]$.

Sweat secretion is qualitatively and quantitatively affected by stimuli such as heat, exercise, emotions, and health status. We recently reported differential sweat EV miRNA secretion in relation to specific exercise [17], supporting the notion that exercise-induced sweat could be used as a source of biomarkers for sport practice.

Both cell free DNA (cfDNA) and extracellular RNA (exRNA) have shown great promise as biomarkers (Reviewed in [18]), therefore our aim was to characterize the nucleic acids associated with sweat EVs. Because our study design was exploratory, our goal was to obtain large quantities of starting material for inventory from the study subjects, and we initially pooled sweat from 13 individuals for nucleic acid analysis. We subsequently also extracted DNA and RNA from sweat of individual collection for analysis. We found human DNA fragments mapping to all chromosomes, but most of the DNA originated from unannotated regions of the human genome. Non-human DNA was found to be derived from skin microbiota, mainly bacteria, but also archaea and viruses. EV-associated RNA species contained a high proportion of tRNA, rRNA and miscRNA, and also approximately 89 miRNA and more than 500 mRNA species. In addition, our NGS data shows the presence of RNA of microbial, fungal and viral origin.

To our knowledge, this is the first published study characterizing EV-associated nucleic acids in exercise induced human sweat.

\section{Results}

\section{Sweat collection and processing}

We collected sweat from people undergoing vigorous biking exercise. We first collected 1,4l of sweat from 13 volunteers of both gender aged from 26 to 56 years at the time of collection, amounts of individual collections were not recorded, the sweat was stored at $-20^{\circ} \mathrm{C}$ and mixed after thawing for processing to DNA and RNA for sequencing (Fig. 1, left side). We collected sweat for RNA from 25 individuals during a $30 \mathrm{~min}$ biking exercise, with the amount of sweat collected from each individual ranging from 6 to $175 \mathrm{ml}$ (Table 1), these collections were processed individually to NGS (Fig. 1), or EV characterization.

\section{DNA isolation and NGS library preparation}

We used DNA from the pooled sample and from three individual collections for whole genome sequencing. The total amount of double stranded DNA recovered was small with a range of 3 to $11 \mathrm{ng}$ total DNA. We chose to make pair-ended libraries with a small genome library kit from Illumina. We were able to get between 10 and $20 \mathrm{M}$ reads per sample. Alignment of the reads to the human genome (GRch38) showed small coverage with some clear hot spots where high number of reads from all samples were detected (Fig. 2A). Coverage on each chromosome (10-30\%) appeared to be dependent of sequencing depth, with the notable exception of the mitochondrial chromosome, which was entirely covered in all samples (Fig. 2B).

\section{DNA sequencing analysis}

The DNA sequencing reads could be assigned to three categories: annotated, unannotated and unmapped. The pooled sample produced the lowest number of reads (Fig. 3A), consisting of 3 categories: annotated (3,8\%), unannotated and unmapped (10\%) with the larger 


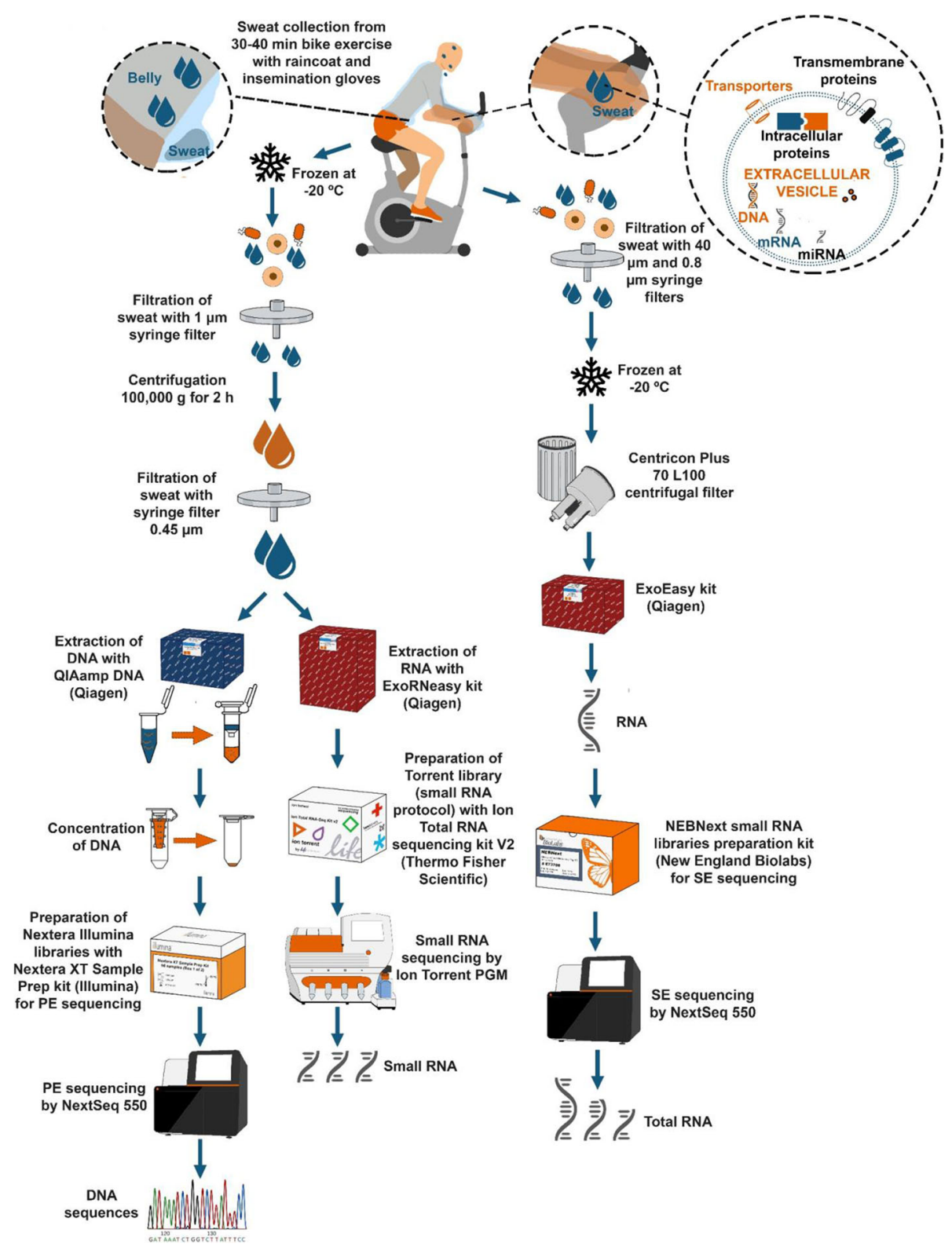

Fig. 1 Workflow. Description of the workflow: left side preparation of EV-enriched sweat DNA. Middle preparation of EV-enriched Sweat RNA from pool for small RNA-seq. Right preparation of EV-enriched sweat RNA from individuals

number aligning with unannotated regions of the human genome $(86,2 \%)$. Samples from individuals had very similar distribution of reads: $2,3 \%$ of reads not aligning to the human genome and $4,5 \%$ aligning to annotated region of the human genome, while the largest category $(93,1 \%)$ corresponded to unannotated region of the human genome (Fig. 3A). The distribution of annotated reads into different biotypes (Fig. 3B) was similar across all 4 samples, the most abundant being protein coding genes $(73-75 \%)$, followed by LincRNA $(6,5-8 \%)$, processed pseudogene $(4,5-5,3 \%)$ and antisense RNA (4-4, $5 \%)$. The coverage of the protein coding genes was very small, except for those encoded by the mitochondrial chromosome.

\section{Sweat particle characterization}

The presence of high amount of mitochondrial DNA suggested the presence of organelles in addition to EVs in the samples. To determine if this was the case, thin sections of filtered $(0,8 \mu \mathrm{m}$ before concentration, 0 , $45 \mu \mathrm{m}$ after) sweat pellets were made from individually processed samples and analyzed by transmission electron microscopy (TEM) (Fig. 4A). We found vesicular structures of varying sizes and appearances in the 
Table 1 Sample Information. Gender, age, sweat volume, and library assignment for each sample

\begin{tabular}{|c|c|c|c|c|}
\hline & Gender & Age & Amount (mL) & $\begin{array}{l}\text { Library } 1 \\
\text { sample } \\
\text { number }\end{array}$ \\
\hline \multirow{4}{*}{$\begin{array}{c}\text { DNA } \\
\text { sequencing }\end{array}$} & MiF & $26-56$ & 80 & pool \\
\hline & M & 56 & 50 & 1 \\
\hline & M & 26 & 50 & 22 \\
\hline & M & 28 & 60 & 23 \\
\hline $\begin{array}{l}\text { Small RNA } \\
\text { sequencing }\end{array}$ & MiF & $26-56$ & 320 & pool \\
\hline \multirow{20}{*}{ RNA-seq } & M & 56 & 100 & 1 \\
\hline & M & 49 & 150 & 8 \\
\hline & M & 25 & 50 & 2 \\
\hline & $M$ & 33 & 45 & 4 \\
\hline & $M$ & 28 & 30 & 5 \\
\hline & $M$ & 24 & 40 & 6 \\
\hline & M & 37 & 80 & 7 \\
\hline & $\mathrm{M}$ & 30 & 36 & 12 \\
\hline & M & 32 & 175 & 15 \\
\hline & $\mathrm{M}$ & 22 & 35 & 16 \\
\hline & $M$ & 31 & 15 & 17 \\
\hline & M & 45 & 78 & 18 \\
\hline & M & 44 & 75 & 19 \\
\hline & $\mathrm{M}$ & 30 & 51 & 20 \\
\hline & $F$ & 24 & 60 & 3 \\
\hline & $F$ & 27 & 33 & 9 \\
\hline & $F$ & 45 & 28 & 10 \\
\hline & $\mathrm{F}$ & 28 & 11 & 11 \\
\hline & $F$ & 49 & 50 & 13 \\
\hline & $F$ & 30 & 15 & 14 \\
\hline \multirow{5}{*}{ Other analysis } & M & 48 & 175 & 21 \\
\hline & M & 24 & 16 & 26 \\
\hline & M & 43 & 15 & 32 \\
\hline & $F$ & 43 & 6 & 39 \\
\hline & $\mathrm{F}$ & 57 & 9 & 44 \\
\hline
\end{tabular}

individual samples, including some with clear double membranes, indicating presence of EVs. Most vesicles were in the $100 \mathrm{~nm}$ range, but some individual samples were richer in smaller and/or larger EVs. We were unable to detect any recognizable mitochondria (Fig. 4A), but bacteria were occasionally detected when $0,45 \mu \mathrm{m}$ filtration was omitted (data not shown).

We chose ExoRNEasy kit to directly purify RNA from concentrated sweat to capture a more diverse selection of EVs [19]. Concentrated individual sweat samples prepared with ExoEasy had variable amounts of welldefined double membrane EVs of 50 to $200 \mathrm{~nm}$ sizes (Fig. 4B, Supplementary Figure 3). Image of negative control (instead of sweat, glove was filled with PBS, which was subsequently processed like volunteer sample) is also shown in Supplemental figure 3. NTA analysis of ExoEasy sweat samples showed 1 peak at around $100 \mathrm{~nm}$ and much smaller peaks for 200 and $300 \mathrm{~nm}$ (Fig. 4C, supplementary Figure 4). Immuno- transmission electron microscopy detected the presence of typical EV markers: CD63 and CD9 in individual sweat EVs and other markers like Glypican1 (Fig. 4D). Presence of CD63 was confirmed by western blotting, while staining for Argonaute 2 and GM130 were negative (Fig. 4E, Supplementary Figure 5). No CD63 was detected in flowthrough from ExoEasy columns and in negative control from gloves (Supplementary Figure 5). Average particle $/ \mathrm{ml}$ of sweat was 475,000 but a wide range was observed (35000-1 million particle $/ \mathrm{ml}$ ) with number of particles per $\mu \mathrm{g}$ of protein being in the range of $0,3-$ $6^{*} 10^{9}$ particles $/ \mu \mathrm{g}$ protein $(n=4)$. We have submitted all relevant data of our experiments to the EV-TRACK knowledgebase (EV-TRACK ID: EV210083) [20].

\section{EV-enriched sweat RNA analysis}

We used the remaining ultracentrifugation pellets from pooled sweat to extract RNA from EV-enriched sweat fraction using ExoRNEasy kit (Fig. 1). Profiling of extracted RNA on bioanalyzer picoChip (Agilent) showed only small RNA with sizes ranging from 20 to $200 \mathrm{bp}$ with no obvious 18 or $28 \mathrm{~s}$ ribosomal RNA (Fig. 5A), subsequently Small RNA protocol was used for the sequencing on Ion Torrent PGM (Thermo Fisher Scientific). A total of 652,280 trimmed reads were used for alignment to the human genome using Bowtie 1. Reads fell into 3 categories: annotated (44,6\%, tRNA reads were included in this category), unannotated $29,6 \%$ and unmapped $24,7 \%$ (Fig. 5B). Over $70 \%$ of the annotated human reads were identified as tRNA, $18,5 \%$ as miscRNA, 5\% mRNA and 1,85\% miRNA (Fig. 5C). 

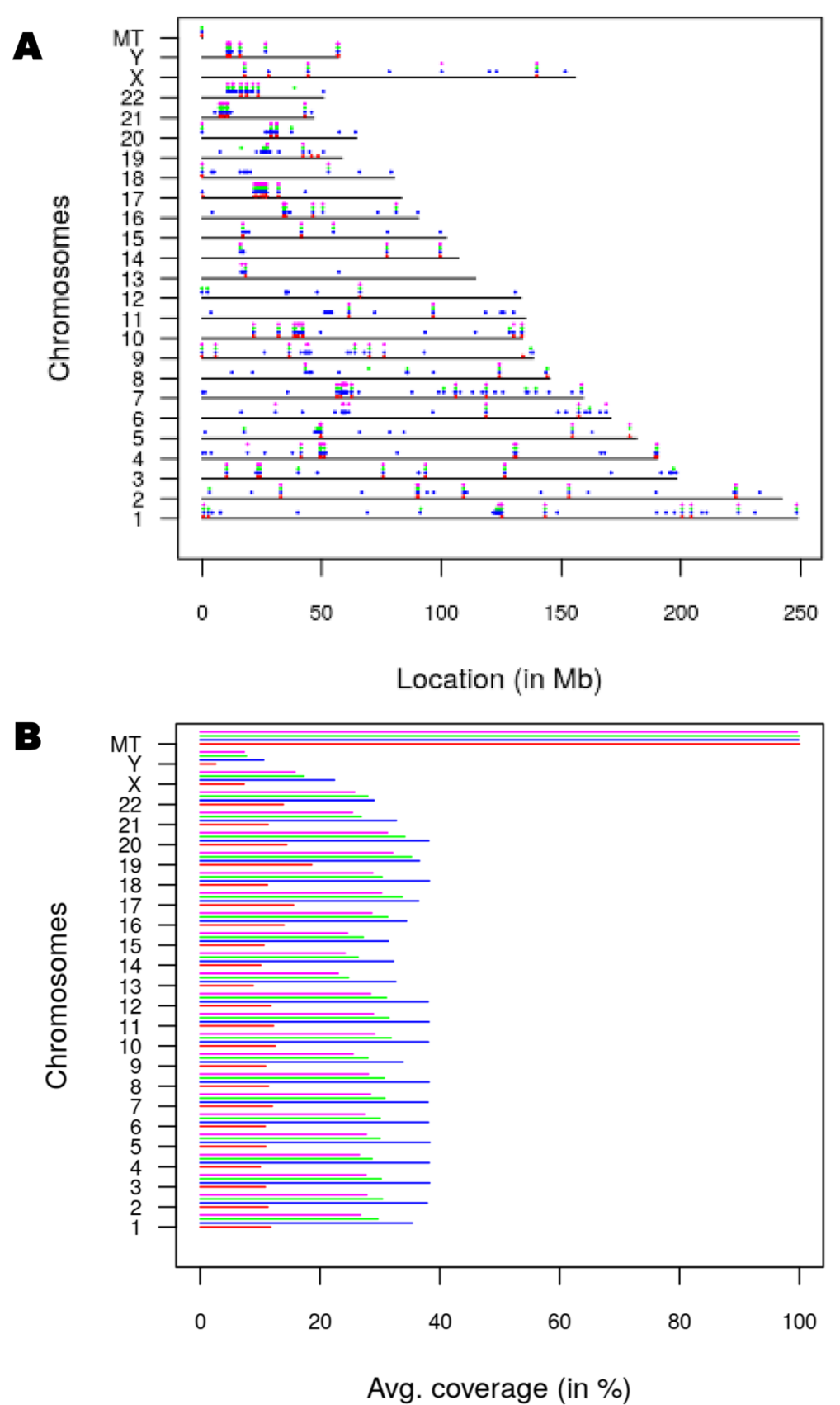

Fig. 2 DNA sequencing results. A: distribution of reads on each chromosome B: coverage for each chromosome. Individual sample indicated by color

\section{miRNA from pooled EV-enriched sweat}

66 miRNAs with read count 10 or higher were identified (Table 2). miR26a-5p was the miRNA with the most reads, followed by miR200c-3p, miRLet7A and miR148a3p (Fig. 6A). We selected 6 miRNAs for testing by qPCR from most abundant (miR26a-5p/692 reads) to low (miR320b/10 reads) on 14 individual samples of sweat RNA (10 were subsequently used for RNA sequencing and 4 additional ones were not, Table 1 ) and compared their level relative to each other, inside each sample. All the miRNAs were detected in all the samples except one, where miR193-3p, was undetectable. In most cases miR21 -5p and miR24-3p were the highest, not miR26a5p (Fig. 6B).

\section{RNA-seq from individual volunteers}

We then prepared RNA from individual sweat collections, from 6 females and 14 males (Table 1) replacing ultracentrifugation by concentration with Centricon Plus-70 columns (Millipore) with a $100 \mathrm{~K} \mathrm{kDa}$ cut-off. 


\section{Read categories}

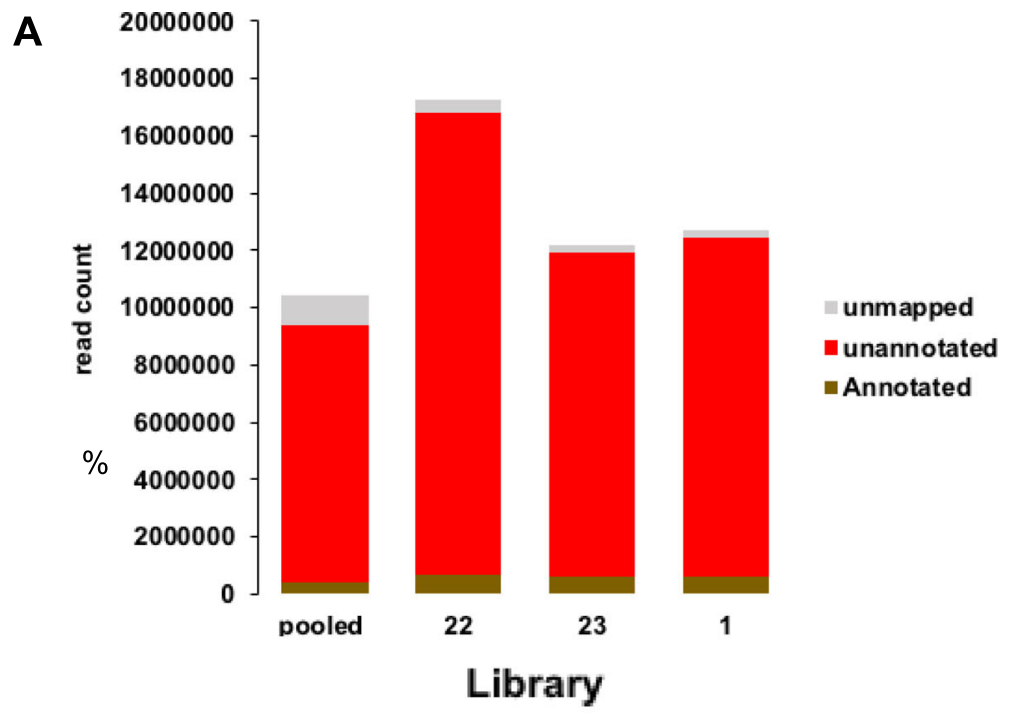

\section{Average percentage of read per biobtype}

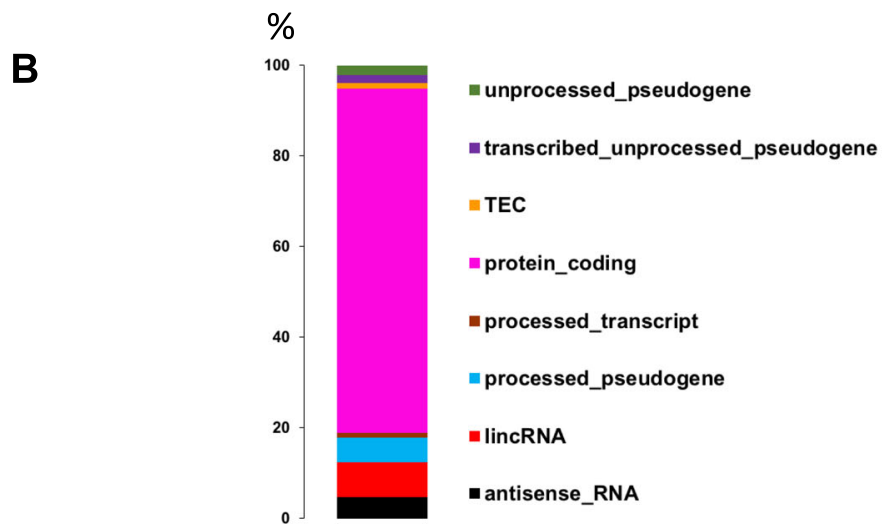

Fig. 3 DNA sequencing results. A: number of reads per category (annotated, unannotated, unmapped) B: percentage of read per biotype

Bioanalyzer (Agilent) RNA profiles of all samples were similar to each other but yields were highly variable (supplementary Figure 1) and below what can be accurately quantified. We selected higher size fragments (145-200 bp) than recommended by the library kit manufacturer (New England Biolab) to limit the number of empty reads and characterize larger RNA species, including protein coding RNA, as a result very few miRNA reads were identified.

After quality trimming, number of reads per sample ranged from 650,000 to 3,4 million (Fig. 7A) with a high number of unmapped reads. As the number of annotated reads per sample were low, we analyzed them together. The distribution into biotypes showed over $50 \%$ identified as tRNA, 28\% as rRNA and LincRNA, miscRNA and protein coding between 8 and 3\% (Fig. 7B). Excluding tRNA and rRNA the top 10 genes identified include 6 miscRNAs with RNY1, RNY4, and RNY4P10 being the most represented, 3 LincRNA, 1 non-coding RNA, 1 snoRNA (SNORD20) (Fig. 8A). As MIR6087 is no longer considered a miRNA, it was omitted from the figure.

Although the function of small nuclear RNA is to participate in mRNA splicing in the nucleus, these small RNA species are abundant in EV-enriched sweat. In Fig. $8 \mathrm{~B}$ the seven most abundant snRNAs represent each between 12 and $15 \%$ of snRNAs identified, all seven represented in B are detected in at least 19 samples (supplementary Table I) and they belong to U1 and U5 families.

The snoRNA's main characterized role is the modification of rRNA, 11 of them are found in significant amounts in EV-enriched sweat, the most abundant type found is box C/D, which guides the 2'-O-methylation of rRNA SNORD20 represent over $40 \%$ of the total, 


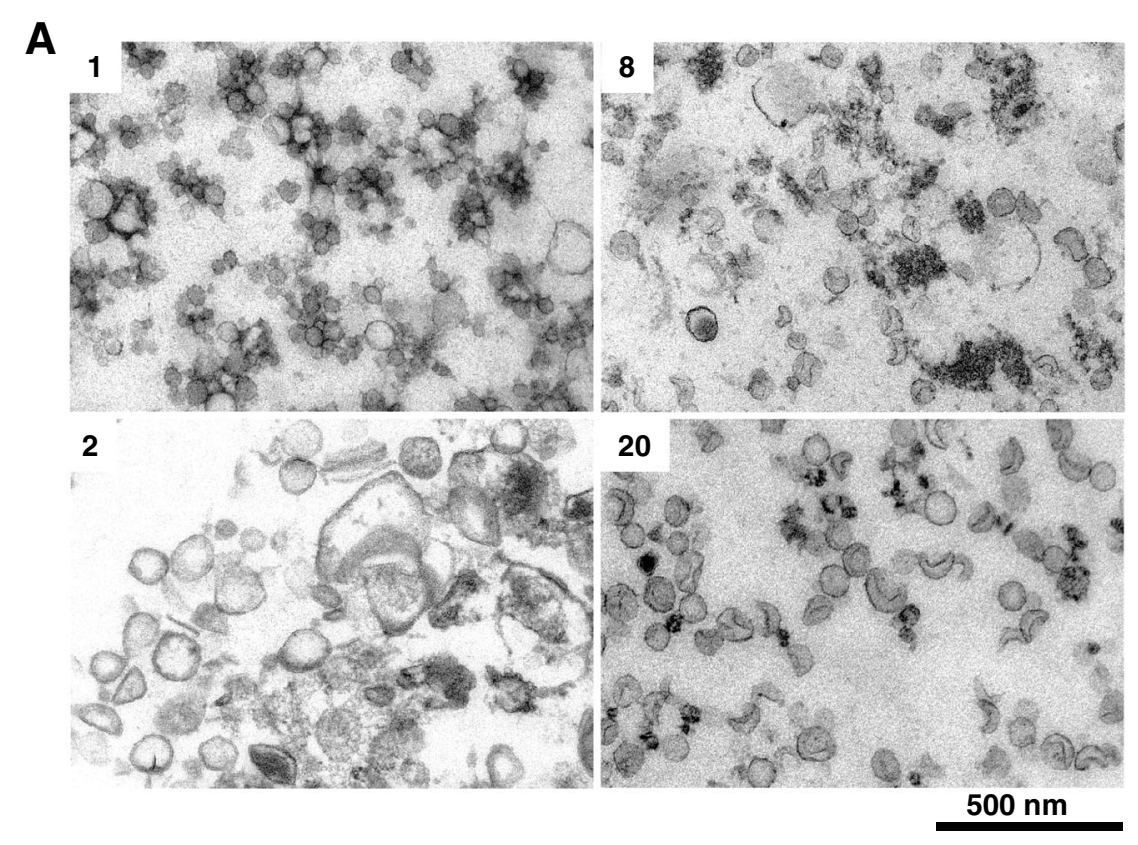

B
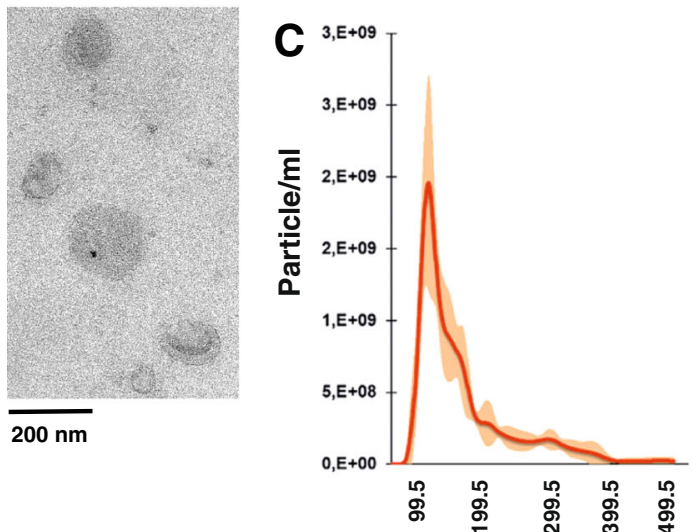

EV size $n m$

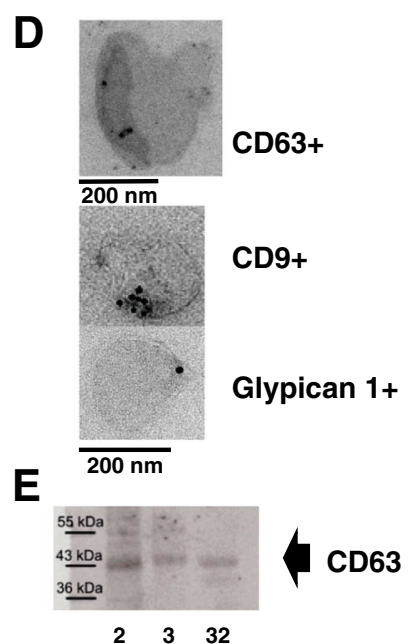

Fig. 4 Sweat particles. Visual characterization of sweat particles. Panels A: TEM, thin sections of plastic embedded pelleted sweat from 4 donors number corresponding to sequencing library (Table 1). B: TEM, negative staining of ExoEasy isolated sweat EVs, C: NTA analysis of Exoeasy EVs, D: TEM, Immunostaining of isolated sweat EVs, E: western blot, protein from Exoeasy sweat preparations were stained with anti-CD63 antibody (ab193349). Full size western blot with region selected marked is shown as supplementary Fig. 6

SNORD90 and SNORD69 (targeting 28 s rRNA) around 20\%, SNORD63 and SNORD101 6\%, SNORD100 4\% (Fig. 8C). SNORD20, SNORD69 and SNORD63 were identified in at least 19 of the 20 samples (Supplementary Table I). Another type of RNA modifying small RNA closely related to snoRNA and located in Cajal bodies (small organelles of the nucleolus of proliferative cells) has 2 well represented members in sweat: scRNA11 and scaRNA4. RNY1 represent over $60 \%$ of misc-RNA biotype's reads, RNY4 represents $16 \%$, RNY4P10 14\% and RNY4P7 2\% (Fig. 8D).
Unprocessed pseudogenes (Fig. 8E) are created by duplication of existing genes and retain intron-exon structure, in this biotype, EIF1P5 is overrepresented with 53\% of the reads mapping to it, while GGTLC4P represent $11 \%$ and AP004607.5 8\%, the remaining unprocessed pseudogenes are mitochondrial genes inserted in nuclear chromosomes and they represent less than 7\% each. Processed pseudogenes, which arise by retrotransposition and are therefore inserted in the genome without intronic sequences were also identified. Top $1 \%$ of reads from RNA-seq included 86 processed pseudogenes. 
A

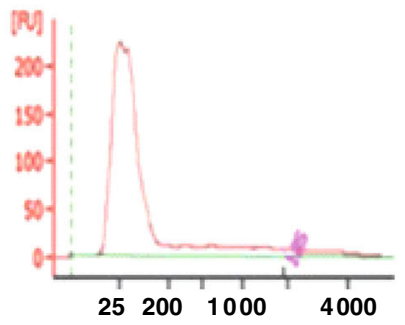

B Read distribution

C Annotated RNA biotype

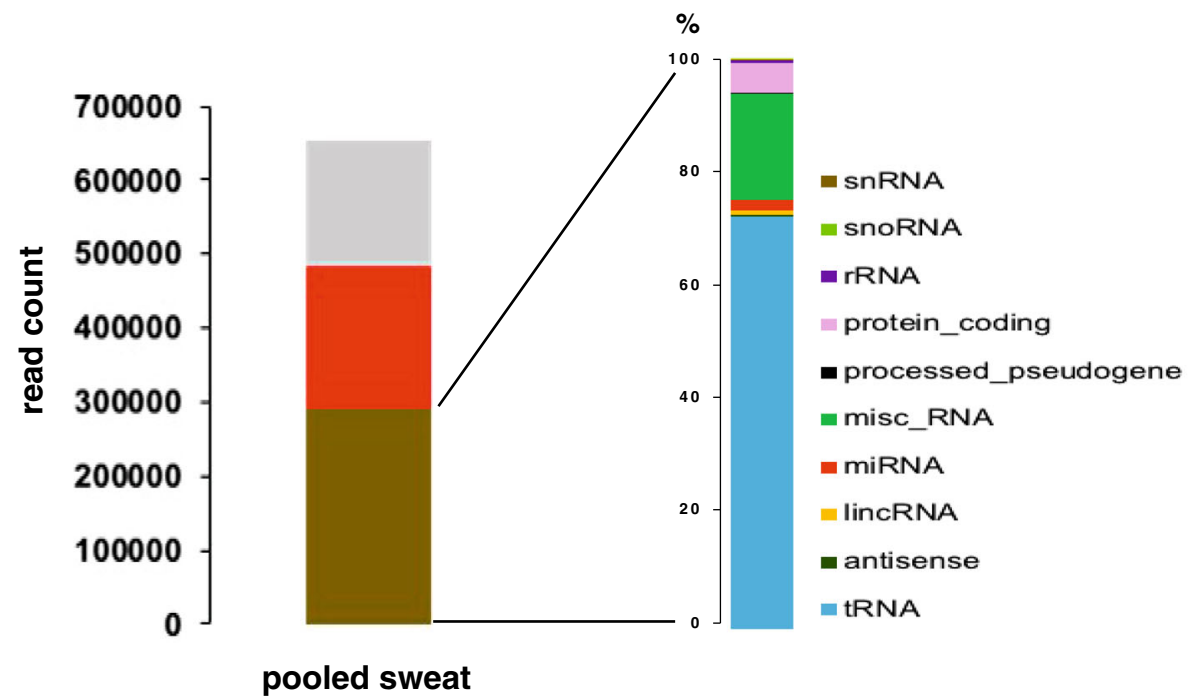

Fig. 5 Sweat smallRNA-seq from pooled sample. A: bioanalyzer profile of sweat Exoeasy RNA, B: read distribution, C: biotype distribution of annotated reads

Piwi-interacting RNA (piRNA) are small noncoding RNA first identified in the germline. They are short: 24$30 \mathrm{bp}$ and their first identified function was to silence transposons. They have since been also identified in other cells and body fluids and may have potential as biomarkers. Only a very small percentage of the reads of each sample can be identified as piRNAs, but 5 piRNAs were identified in all 20 samples, and 6 in 19 samples (Supplementary Figure 2). Another 1000 piRNAs were sporadically detected in 3 or less samples. Other noncoding RNA usually associated with EVs like Vault RNA were also identified in the majority of the samples (Supplementary Table 1).

\section{Sweat $m R N A$}

The most abundant mRNAs in sweat are encoded by the mitochondrial genome, followed by a mitochondrial transcript encoded by a nuclear gene, MTRNR2L6 (Fig. 9A). Comparison with a recent report of the transcriptome and proteome of human eccrine gland shows that $85 \%$ of mRNAs found in EV-enriched sweat overlap with mRNA from sweat eccrine gland, with only $14.4 \%$ unique to EV-enriched sweat (Fig. 9B).

For enrichment analysis of GO annotation we selected transcript with FPKM values bigger than 25, most of the transcript encode either translation related proteins, nucleic acid binding protein or focal adhesion protein. Biological Processes involve energy metabolism, protein synthesis and nucleic acid binding (Fig. 9C), the most represented cell components are ribosomal (Fig. 9D). In addition to the abundant mRNA species (Table 3), 6675 additional gene products were detectable in 1-3 samples with FPKM value bigger than 0 .

Because the reads for mRNA could be detected on several exons and alignment with STAR showed that some of these reads were spliced, we checked the presence of spliced mRNA in EV-enriched sweat by RT-PCR with primers designed for amplification across splice junctions. The most abundant and largely distributed in most of the samples was (ferritin light chain) FTL mRNA, FTL gene has 4 exons, and using primers designed to amplify mRNA of the last 2 exons (3 and 4), we were able to amplify cDNA from several samples 
Table 2 Sweat miRNA pooled samples. miRNA with read count 10 or above

\begin{tabular}{|c|c|c|c|c|c|}
\hline \hline miRNA & $\begin{array}{c}\text { read } \\
\text { count }\end{array}$ & miRNA & $\begin{array}{c}\text { read } \\
\text { cout }\end{array}$ & RNA & read count \\
\hline hsa-miR-26a-5p & 692 & hsa-miR-29c-3p & 97 & hsa-miR-140-3p & 31 \\
\hline hsa-miR-200c-3p & 467 & hsa-miR-182-5p & 89 & hsa-miR-378a-3p & 25 \\
\hline hsa-let-7a-5p & 414 & hsa-miR-223-3p & 89 & hsa-miR-93-5p & 21 \\
\hline hsa-miR-148a-3p & 397 & hsa-miR-200b-3p & 81 & hsa-miR-590-5p & 19 \\
\hline hsa-miR-191-5p & 326 & hsa-miR-342-3p & 80 & hsa-miR-335-5p & 18 \\
\hline hsa-miR-30b-5p & 274 & hsa-miR-141-3p & 72 & hsa-miR-455-3p & 18 \\
\hline hsa-miR-23b-3p & 259 & hsa-miR-16-5p & 72 & hsa-miR-197-3p & 17 \\
\hline hsa-miR-29b-3p & 256 & hsa-miR-27a-3p & 67 & hsa-miR-34a-5p & 17 \\
\hline hsa-miR-24-3p & 240 & hsa-let-7c-5p & 63 & hsa-miR-101-3p & 16 \\
\hline hsa-miR-23a-3p & 214 & hsa-miR-100-5p & 58 & hsa-miR-22-3p & 16 \\
\hline hsa-miR-30d-5p & 210 & hsa-miR-193a-5p & 52 & hsa-miR-1247-5p & 15 \\
\hline hsa-let-7b-5p & 181 & hsa-miR-375-3p & 52 & hsa-miR-19a-3p & 15 \\
\hline hsa-miR-30c-5p & 172 & hsa-miR-125a-5p & 48 & hsa-let-7d-5p & 14 \\
\hline hsa-miR-21-5p & 167 & hsa-miR-26b-5p & 48 & hsa-miR-183-5p & 14 \\
\hline hsa-miR-205-5p & 157 & hsa-let-7g-5p & 47 & hsa-miR-484 & 14 \\
\hline hsa-miR-125b-5p & 144 & hsa-miR-320a-3p & 40 & hsa-miR-92a-3p & 14 \\
\hline hsa-miR-19b-3p & 135 & hsa-miR-30e-5p & 37 & hsa-miR-107 & 12 \\
\hline hsa-miR-30a-5p & 123 & hsa-miR-193b-3p & 33 & hsa-miR-452-5p & 12 \\
\hline hsa-miR-196a-5p & 119 & hsa-miR-425-5p & 33 & hsa-miR-29c-5p & 11 \\
\hline hsa-let-7f-5p & 113 & hsa-miR-574-3p & 33 & hsa-miR-429 & 11 \\
\hline hsa-miR-29a-3p & 108 & hsa-miR-200a-3p & 32 & hsa-miR-95-3p & 11 \\
\hline hsa-miR-99a-5p & 98 & hsa-miR-27b-3p & 32 & hsa-miR-320b & 10 \\
\hline
\end{tabular}

(Fig. 10A). YWHAE gene spans across 7 exons, on a total DNA length of $55 \mathrm{~kb}$, with a reverse PCR primer spanning exon 6 and 7 together and forward primer on exon 5 we amplified a fragment of the expected size in 2 out of 3 samples (Fig. 10B, supplementary Figure 7). We were able to amplify several other mRNA at least across one splice junction indicating that even if the RNA is fragmented it is processed (supplementary figure 7).

\section{Metagenomic nucleic acid Microbial DNA and RNA}

DNA-seq had 5-9\% of unmapped reads, and to determine their origin, the reads were assembled and aligned against the metagenome and the main taxonomical orders were identified. In addition to bacterial DNA, there was a small proportion of virus and archaeal DNA. Dominant bacterial orders were Proteobacteria, Actinobacteria followed by equal proportion of Bacteroidetes and Firmicutes (Fig. 11), a distribution typical of skin microbiota.

RNA-seq produced much higher amounts of unmapped reads, and metagenomic analysis attributed the highest proportion of them to bacteria, but fungi and virus could also be identified. The distribution of the main bacterial orders was relatively similar to what we observe for DNA, except for a larger proportion of Firmicutes than Bacteroidetes (Fig. 11), again a distribution consistent with the skin microbiome.

A fraction of the sequences identified corresponded to microbial protein coding genes. We retrieved the protein IDs with GO annotations from UniProt database, then counted the GO annotations. The cell component annotations showed mostly integral components of membrane and cytoplasm for both DNA and RNA sequencing. DNA sequencing included also at least 20 protein coding genes with annotations for cell, ribosome and integral component of plasma membrane, while RNA-seq included periplasmic space linked mRNA (Fig. 12A). The molecular functions of protein coding genes identified in both DNA-seq and RNA-seq were predominantly ATP binding, DNA binding and metal ion binding (Fig. 12B).

\section{Viral DNA}

We found 2 types of viral DNA, from human virus: papilloma, polyoma, herpes virus and from bacteriophages infecting the bacteria from the skin. Viral sequences 


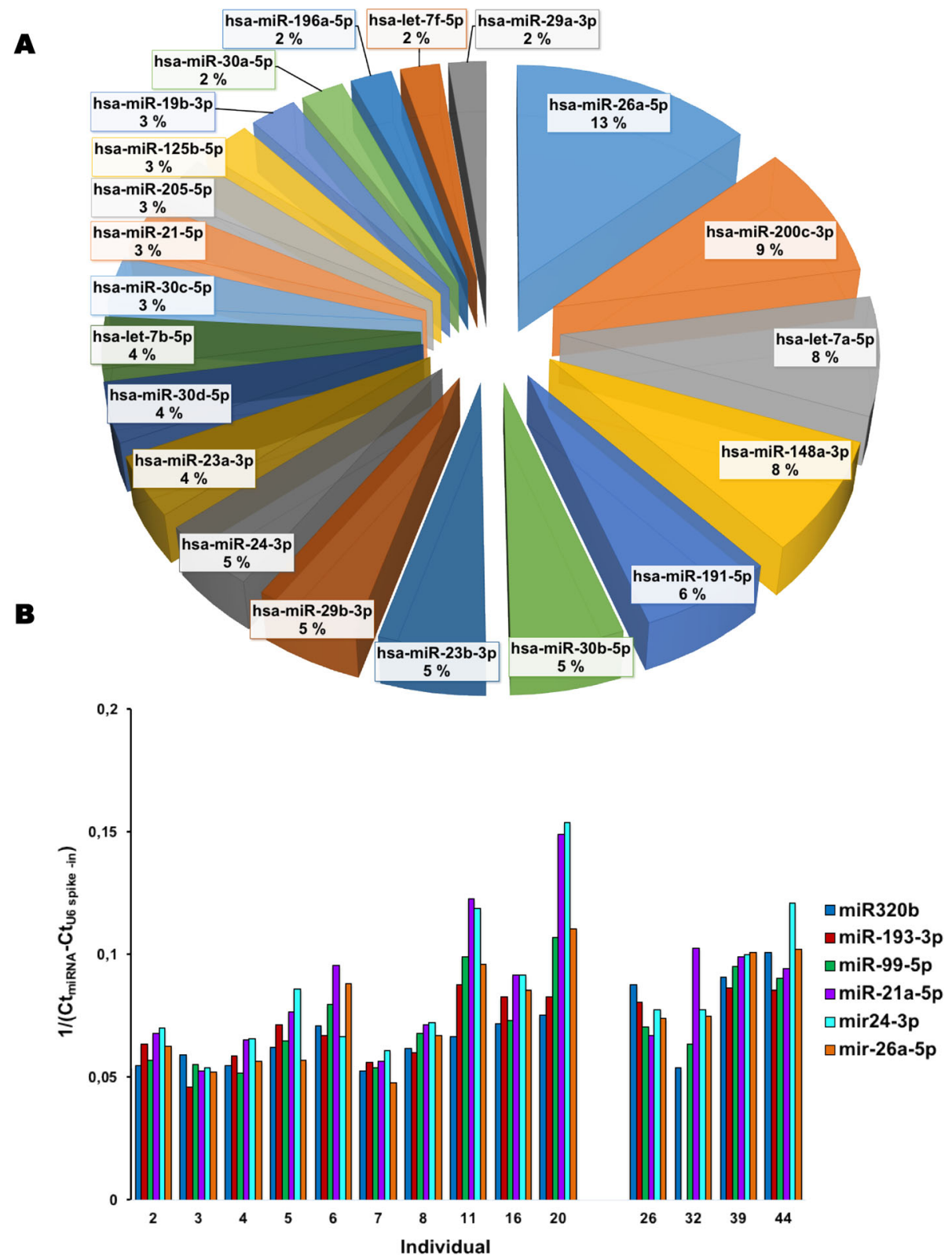

Fig. 6 EV-enriched sweat /associated miRNA. A: most represented miRNA (minimum read count > 100) in pooled sweat sample. B: Comparison of specific miRNA level in individual samples. Last 4 samples were not sequenced

represent $13 \%$ of the total identified, with papilloma sequences representing $24 \%$ of viral sequences, polyomavirus represent $5 \%$ and herpes $2 \%$. Only a portion of the DNA identified encodes identified protein, but from papillomavirus 6 protein coding genes can be identified (out of a total of 8), capsid protein major L1 and Minor L2, replication protein E1, regulatory protein E2, and protein E4 and E6. From polyoma viruses, and Merkel cell polyoma virus, Small $\mathrm{T}$ antigen and capsid protein Vp1 (total encoded by viral genome: 5-9 protein) were identified and from human Cytomegalovirus, only uncharacterized protein UL126 (more than 165 protein coding genes). The gene encoded are capsid protein, regulatory and replication protein from papilloma virus and capsid and small $\mathrm{T}$ antigen from polyomavirus (Table 4).

Bacterial phages are represented by a variety of genes, 96 are uncharacterized, 274 genes encode phage structural protein and enzymes (Table 5), which molecular functions include mainly DNA binding, helicase, hydrolase and endonuclease. Most components of the phage genome are represented (Table 5). 


\section{$\mathbf{A}$}

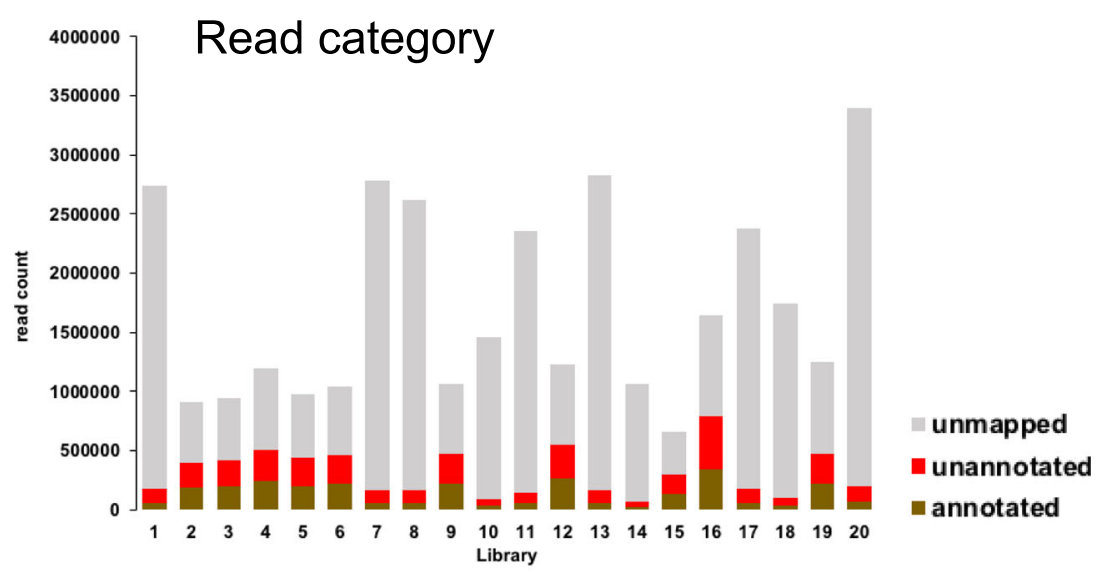

B Annotated reads biotypes (average)

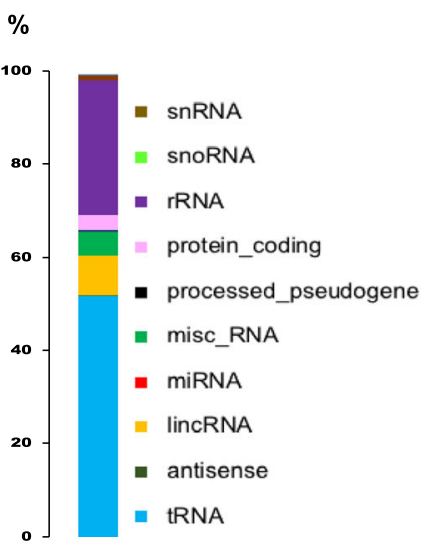

Fig. 7 RNA-seq from individual EV-enriched sweat sample. A: Distribution of reads from each library in categories, B: distribution of annotated reads in biotypes (average from all 20 samples)

\section{Discussion}

The skin is usually considered a hostile environment for nucleic acids, particularly RNA, because of the presence of nucleases, but inside EVs or other types of complexes, nucleic acids are likely to be protected. EVs have now been found in most biofluids, including sweat [16, 17], but proper inventory of sweat nucleic acids is still needed to determine the potential usefulness of sweat for nucleic acid biomarker discovery.

The most covered DNA and the most represented mRNA in the sweat samples were from mitochondrial origin. Mitochondria have been shown to be released by cells during oxidative stress [21], and to be transported in EVs [22], but we could not detect any intact mitochondria by TEM in our preparations. Mitochondrial protein have been reported in melanoma EVs [23] so we can speculate that the mitochondrial DNA in our samples was a result of mitophagy, which is a normal part of the skin's aging process [24, 25]; Alternatively, in context of the skin, mitochondria may also be transported out of melanocyte during melanosome release, as the two organelles are tightly bound during melanogenesis [26].

On the other hand, total nuclear DNA is more sparsely represented with very few counts from coding genes while some unannotated regions are highly overrepresented in all four samples, indicating that these sequences may not be randomly secreted. DNA as EV cargo is still controversial [27], as in most cases it is not protected from DNAse and might be just sticking to the EV surface, although there are exceptions like giant oncosomes [28], or physiological process to protect cells from activation of DNA-damage-response and cell cycle arrest or apoptosis [29] and parasite like plasmodium use DNA-loaded EVs to prime host cells for infection [30].

It is unclear how the characterized sweat DNA is associated with sweat EVs, but it is very likely that some of it is associated with apoptotic bodies resulting from sebum secretion collected by the flow of sweat during exercise, which is consistent with the presence of nucleic acids from bacteria typical of the sebaceous glands, such as 


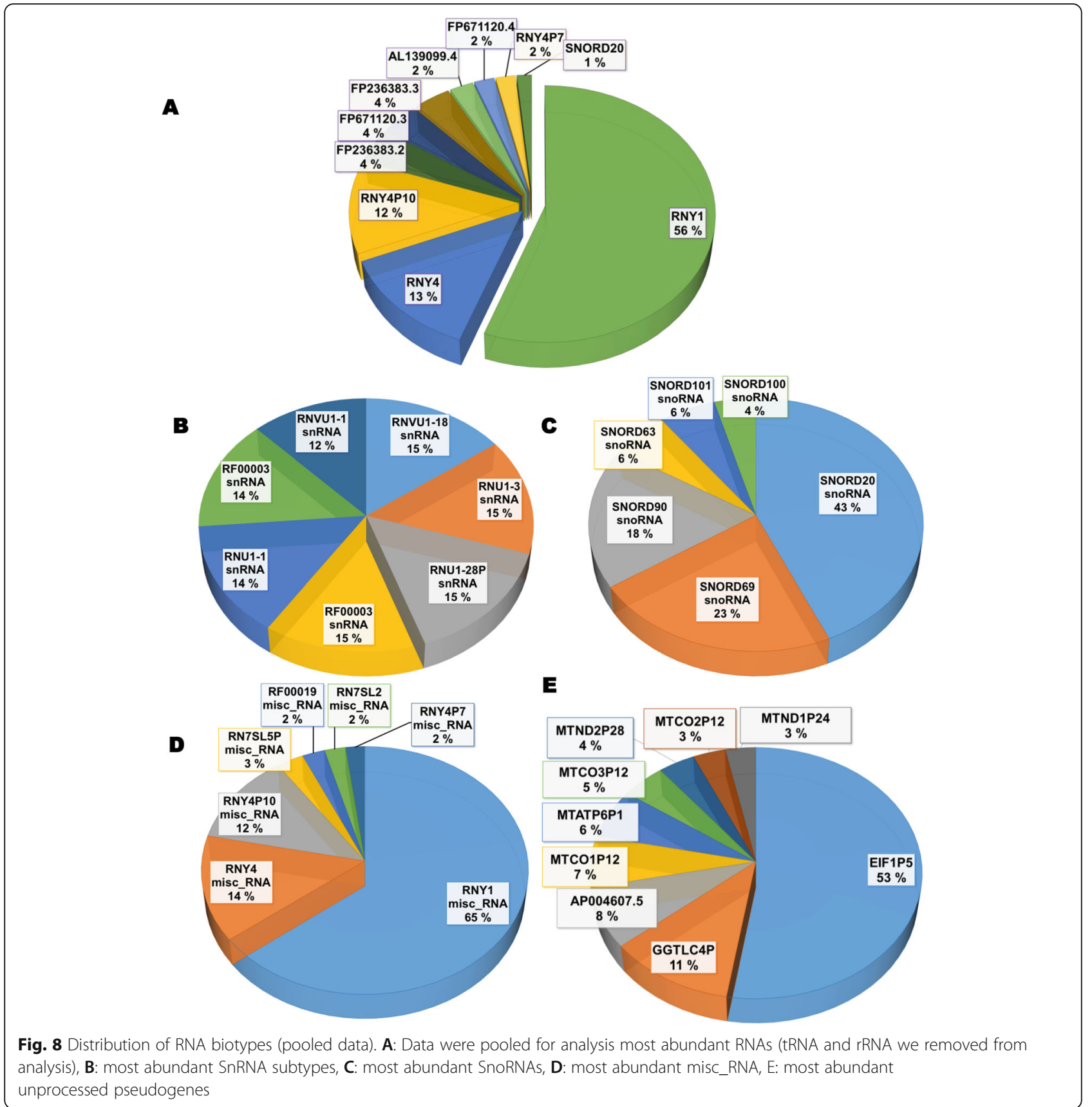

Propionibacterium (Cutibacterium) acnes and their associated bacteriophages.

Small RNA sequencing with small sample quantity is challenging, resulting in a large proportion of unmapped reads. EVs have been shown to have RNA both on their surfaces and inside, but most reports show that the larger RNA species (larger than $200 \mathrm{bp}$ ) are absent altogether. Best studied EV-associated RNAs are miRNAs. Even though we did not use RNAse, obtaining detectable amount of RNA proved challenging. Even with a small RNA protocol, our samples were mostly tRNAs and miscRNA with a small representation of miRNAs. We were nevertheless able to confirm the presence of even the lowest represented miRNA in most samples tested using qPCR. Based on our list of miRNA we were able to identify miR21-5p and miR26a-5p as regulated by exercise [17].

Using an unbiased sequencing approach with individual samples confirmed the predominance of tRNA, rRNA and miscRNA observed in many other EV RNA studies [31]. It was more surprising to identify more than 500 protein coding RNA detectable in at least 9 
A
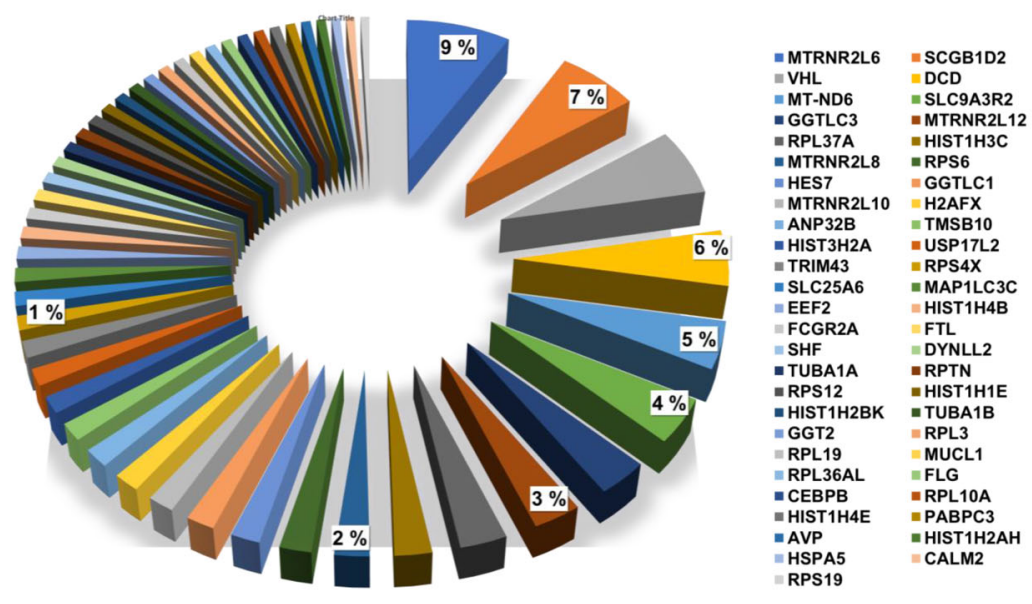

B

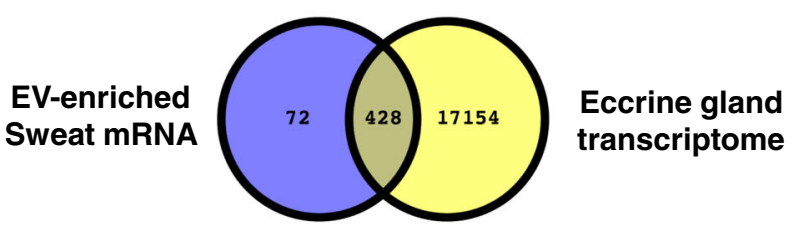

C mRNA biological processes

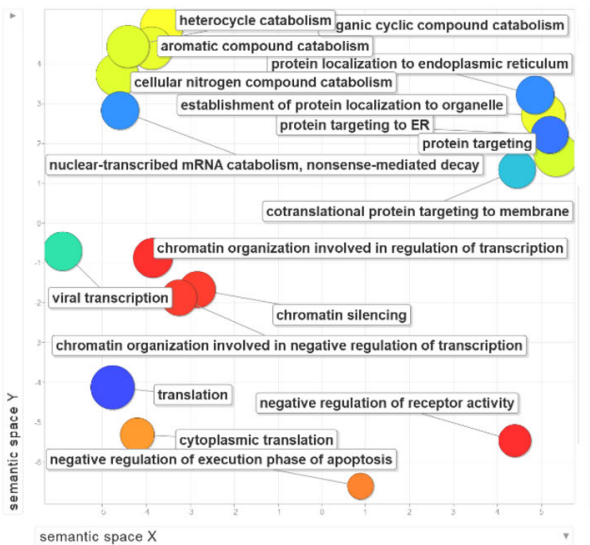

D mRNA cellular components

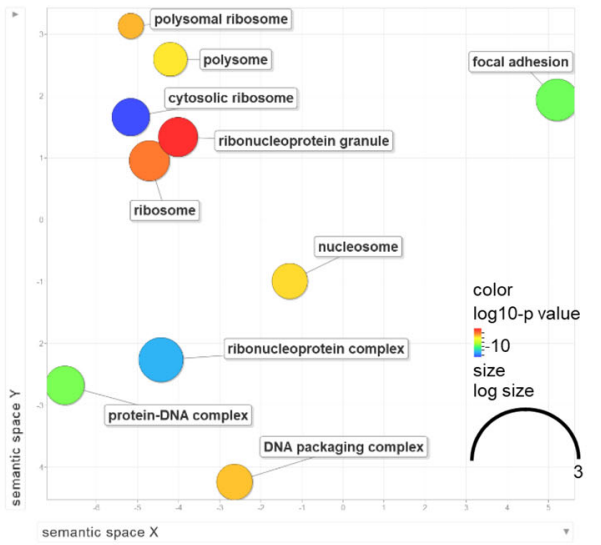

Fig. 9 EV-enriched Sweat mRNA (pooled data). A: most represented mRNA, B: overlap between human eccrine gland transcriptome and EVenriched sweat mRNA, $\mathbf{C}$ : enriched biological processes in EV-enriched sweat mRNA, D: enriched cellular components, based on GO annotations, colors represent $\log 10$-value representation using Revigo

samples and to find that some of them are spanning several spliced introns. Previously published reports point to several explanations for the presence of mRNA. The mRNA exist in co-purified protein complexes [31] or bound to secreted ribosomes [32], which partly protect the mRNA from degradation. It was also interesting to see that a large proportion of the EV-enriched sweat mRNAs are common to the transcriptome of the human eccrine gland [33]. GO analysis mostly shows enrichment in ribosomal components and translation but no clear cellular origin as most of the mRNAs identified tend to be ubiquitously expressed. While it is possible that EV-enriched sweat indeed contain full length functional mRNAs it is more likely reflecting the functional status of the cells that release EVs to sweat, without any particular function of its own.

Of further interest is the presence of microbiome derived particles. The most abundant phyla identified by NGS analysis were Proteobacteria, Actinobacteria, Firmicutes and Bacteroidetes, which are usually found on human arms, hands, and axilla. Proteobacteria are dominant on face and torso [34]. City scale 
Table 3 mRNA with highest FPKM IN RNA-SEQ (pooled data from individual). mRNA, including mitochondrial mRNA most represented in sweat, with chromosome location and ensemble gene ID

\begin{tabular}{|c|c|c|c|c|c|}
\hline gene name & Chromosome & gene id & gene name & Chromosome & gene id \\
\hline MT-CYB & \begin{tabular}{|c|} 
MT \\
\end{tabular} & ENSG00000198727 & AVP & 20 & ENSG00000101200 \\
\hline MT-CO1 & MT & ENSG00000198804 & HIST1H2AH & 6 & ENSG00000274997 \\
\hline MTRNR2L6 & 7 & ENSG00000270672 & HSPA5 & 9 & ENSG00000044574 \\
\hline SCGB1D2 & 11 & ENSG00000124935 & CALM2 & 2 & ENSG00000143933 \\
\hline VHL & 3 & ENSG00000134086 & RPS19 & 19 & ENSG00000105372 \\
\hline DCD & 12 & ENSG00000161634 & PPP1R15A & 19 & ENSG000000087074 \\
\hline MT-ND6 & MT & ENSG00000198695 & NACA2 & 17 & ENSG00000253506 \\
\hline SLC9A3R2 & 16 & ENSG00000065054 & AC093762.1 & 2 & ENSG00000284635 \\
\hline GGTLC3 & 22 & ENSG00000274252 & HRNR & 1 & ENSG00000197915 \\
\hline MTRNR2L12 & 3 & ENSG00000269028 & DEFB126 & 20 & ENSG00000125788 \\
\hline RPL37A & 2 & ENSG00000197756 & AL136454.1 & 1 & ENSG00000231767 \\
\hline HIST1H3C & 6 & ENSG00000278272 & YBX1 & 1 & ENSG00000065978 \\
\hline MTRNR2L8 & 11 & ENSG00000255823 & PEA15 & 1 & ENSG00000162734 \\
\hline RPS6 & 9 & ENSG00000137154 & MTRNR2L11 & 1 & ENSG00000270188 \\
\hline HES7 & 17 & ENSG00000179111 & NDUFS5 & 1 & ENSG00000168653 \\
\hline GGTLC1 & 20 & ENSG00000149435 & SETSIP & 1 & ENSG00000230667 \\
\hline MTRNR2L10 & $x$ & ENSG00000256045 & GOLPH3 & 5 & ENSG00000113384 \\
\hline H2AFX & 11 & ENSG00000188486 & HIST1H4K & 6 & ENSG00000273542 \\
\hline ANP32B & 9 & ENSG00000136938 & ElF4H & 7 & ENSG00000106682 \\
\hline TMSB10 & 2 & ENSG00000034510 & RPS8 & 1 & ENSG00000142937 \\
\hline HIST3H2A & 1 & ENSG00000181218 & MUC6 & 11 & ENSG00000184956 \\
\hline USP17L2 & 8 & ENSG00000223443 & RPS24 & 10 & ENSG00000138326 \\
\hline TRIM43 & 2 & ENSG00000144015 & RRAGA & 9 & ENSG00000155876 \\
\hline RPS4X & $x$ & ENSG00000198034 & EElF4EBP1 & 8 & ENSG00000187840 \\
\hline SLC25A6 & $x$ & ENSG00000169100 & POP7 & 7 & ENSG00000172336 \\
\hline MAP1LC3C & 1 & ENSG00000197769 & MTRNR2L1 & 17 & ENSG00000256618 \\
\hline EEF2 & 19 & ENSG00000167658 & RPL41 & 12 & ENSG00000229117 \\
\hline HIST1H4B & 6 & ENSG00000278705 & SRSF1 & 17 & ENSG00000136450 \\
\hline FCGR2A & 1 & ENSG00000143226 & RNF133 & 7 & ENSG00000188050 \\
\hline FTL & 19 & ENSG00000087086 & ARF6 & 14 & ENSG00000165527 \\
\hline SHF & 15 & ENSG00000138606 & RPS21 & 20 & ENSG00000171858 \\
\hline DYNLL2 & 17 & ENSG00000264364 & MTRNR2L3 & 20 & ENSG00000250222 \\
\hline TUBA1A & 12 & ENSG00000167552 & HIST2H3D & 1 & ENSG00000183598 \\
\hline RPTN & 1 & ENSG00000215853 & JUNB & 19 & ENSG00000171223 \\
\hline RPS12 & 6 & ENSG00000112306 & HOXA5 & 7 & ENSG00000106004 \\
\hline HIST1H1E & 6 & ENSG00000168298 & PPIF & 10 & ENSG00000108179 \\
\hline HIST1H2BK & 6 & ENSG00000197903 & CSNK2A3 & 11 & ENSG00000254598 \\
\hline TUBA1B & 12 & ENSG00000123416 & RPL8 & 8 & ENSG00000161016 \\
\hline GGT2 & 22 & ENSG00000133475 & FBXL14 & 12 & ENSG00000171823 \\
\hline RPL3 & 22 & ENSG00000100316 & SSC4D & 7 & ENSG00000146700 \\
\hline RPL19 & 17 & ENSG00000108298 & ATF4 & 22 & ENSG00000128272 \\
\hline MUCL1 & 12 & ENSGO0000172551 & SAMD1 & 19 & ENSG00000141858 \\
\hline RPL36AL & 14 & ENSG00000165502 & PSMB3 & 17 & ENSG00000277791 \\
\hline FLG & 1 & ENSG00000143631 & MYH9 & 22 & ENSG00000100345 \\
\hline CEBPB & 20 & ENSG00000172216 & PABPC1 & 8 & ENSG00000070756 \\
\hline RPL10A & 6 & ENSG00000198755 & HIST1H2AM & 6 & ENSG00000278677 \\
\hline HIST1HAE & 6 & ENSG00000276966 & HIST1H4I & 6 & ENSG00000276180 \\
\hline PABPC 3 & 13 & ENSG00000151846 & RPL37 & 5 & ENSG00000145592 \\
\hline
\end{tabular}

metagenomics studies like the one performed in New York city underground system revealed a lot of information about underground users and their skin microbiome and highlighted that each individual sheds genetic information from their skin, both from their own genome and from their own microbiome, which can be retrieved for analysis [35]. Our data is consistent with that largescale study result, and the conclusion that the human DNA collected in these metagenomics studies is most likely derived from human sweat.
Further studies are needed to determine if any of the RNAs found in our study are of clinical value, SNPs in some mRNA identified are associated with known diseases and could be further studied. For example, CALM2, which mRNA was identified in all the samples, has SNPs associated with cardiac arrhythmia and sudden death of young people after exercise [36]. Larger scale studies could determine if it is possible to identify clinically associated variants from sweat RNA. Other abundant misc. RNAs such as RNY1,3 and 4 are also 


\section{A}

FTL (Ferritin Light Chain)

$1,6 \mathrm{~kb}$

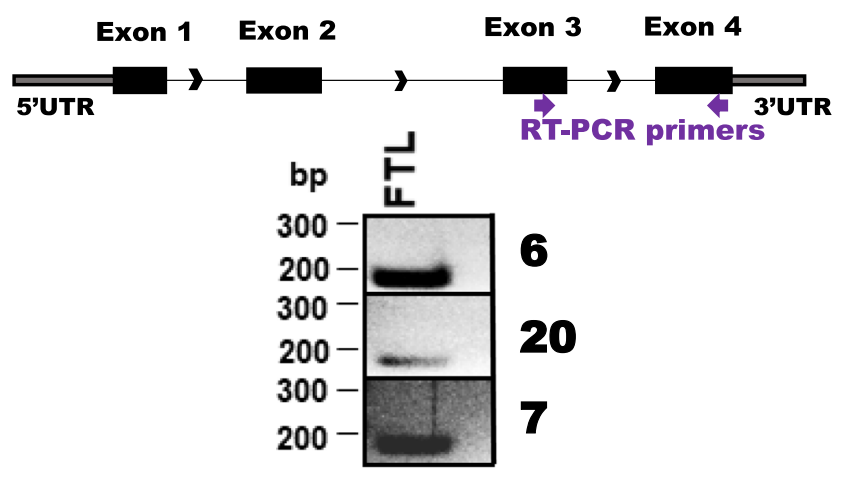

$\mathbf{B}$

YWHAE (14-3-3 Protein Epsilon)

$55 \mathbf{k b}$
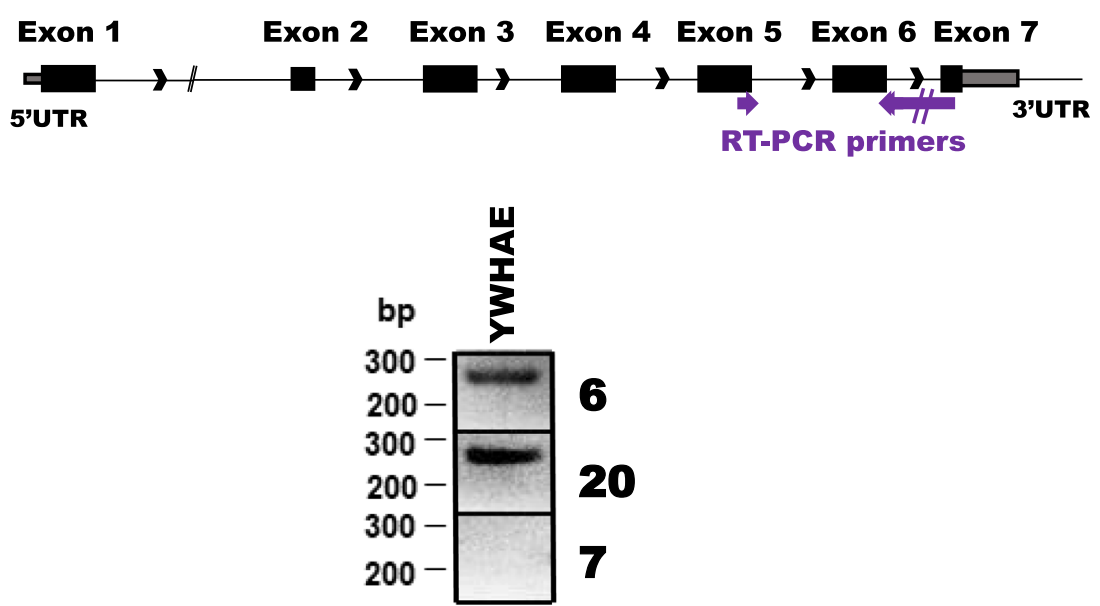

Fig. 10 spliced mRNA are detectable in EV-enriched sweat. A: Ferritin Light Chain Gene, PCR primers localization (arrows) with RT-PCR amplified DNA visualized on 2\% agarose gel, B: 14-3-3 Protein Epsilon gene with PCR primers spanning exon5,6 and 7, below product on agarose gels showing amplification across the 3 exons in 2 out of 3 tested samples. The full size gels with region selected marked are shown in supplemental Fig. 7

considered to have diagnostic potential for inflammatory diseases [37] and cancer [38].

\section{Study limitations}

Sweat as a biofluid presents many challenges, and the most important ones in the frame of this study are that the human skin is exposed to the environment, and it is an ecosystem where many organisms live. Skin secretions, including sweat, are metabolised by skin microbes, and the skin microbes secrete their own products, including outer membrane vesicles. The non-human nucleic acids we identified originated primarily from the skin microbiota, but also possibly from clothing and working surfaces, or from the collection material. Distinguishing contaminant nucleic acids in human sweat is especially challenging, since contaminants introduced in the process of sample handling are also mainly derived from human skin secretions. RNA extraction columns have been shown to contain contaminant RNA, and a small RNA sequencing data set available from data repository also show the presence of these contaminating RNAs [39]. Capturing total EVs from biofluids is still not possible by standard methods, and the choice of approach taken here therefore represents a trade-off between quantity/diversity and purity. The ExoRNEasy kit captures EVs on a filter and then proceeds directly to on-filter lysis for RNA isolation. For a biofluid like sweat, in which the EV quantity depends on individual factors and also ambient temperature, hydration status and length and intensity of exercise, capturing particles 


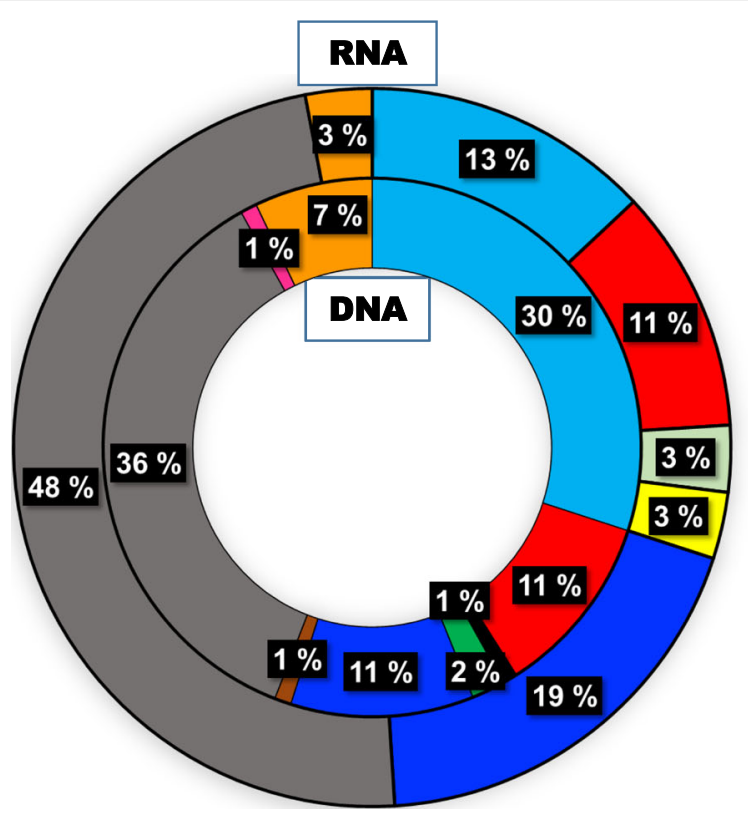

$\square$ Actinobacteria

$\square$ Bacteroidetes

$\square$ Chlamidya

$\square$ Chrysiogenetes

- Cyanobacteria

$\square$ Deinococcus-Thermus

Firmicutes

$\square$ Planctomycetes

$\square$ Proteobacteria

$\square$ Verrucomicrobia

$\square$ Other

Fig. 11 Sweat Metagenomics. Most represented bacterial orders in RNA sequencing (outer circle) and DNA sequencing (inner circle)

appeared to be a good choice for comparing heavy and light sweat producers. But as humans are constantly secreting a small quantity of eccrine sweat, alternative methods of collection might be more appropriate for biomarker development, including for sport-associated studies.

In line with MISEV2018 recommendations [40] and because we are aware that our type of preparation is not of high purity, we have used the term sweat particles, or EV-enriched preparation in this report. We are describing preparation methods in detail in the method section and have submitted the study to EV-track (EV-TRACK ID: EV210083), EV-metric 14\% for the DNA preparation and $50 \%$ for the RNA study.

\section{Conclusions}

Our data shows that that sweat particles are a good source of nucleic acid as has been reported for other biofluids. As the skin surface offers a site for noninvasive and real-time sample collection our study opens the path for future sweat EV biomarkers discovery.

\section{Methods}

\section{Volunteers}

Adult volunteers were recruited among persons of different ethnic background residing in Northern Finland in Oulu area (Table 1). Volunteers were given information about the study and provided limited health and fitness self-assessment in a form and informed consent. Ethical permission (EETTMK:110/2015) was granted by the ethical committee of Oulu University medical School according to the Finnish Medical Research Act (488/
1999). Volunteers were asked to avoid using soap and perfume for $24 \mathrm{~h}$ before the exercise and to shower with water only for $15 \mathrm{~min}$ immediately before exercise to remove dust and other environmental contaminant residues from the skin. These studies were performed according to the Declaration of Helsinki on research involving humans. The study protocol named RUBY was approved by the Ethical Committee at the Northern Ostrobothnia Hospital District in Oulu under Study Diary Number 110/2015. Participants in the study were given information about the study and signed informed consent forms approved by the ethics committee.

Pooled sweat processing and nucleic acid analysis We first collected large amount of sweat from 13 people of both genders aged 26 to 56 years, during a 40 min biking exercise (Fig. 1). Collected sweat was kept at -20 degrees until processing. After thawing, pooled sweat was filtered on $0,45 \mu \mathrm{m}$ Milipore PES filters, then centrifuged for $2 \mathrm{~h}$ at $108000 \mathrm{x} \mathrm{g}$ in an Avanti J-30I centrifuge (Beckman) using JA30-50 rotor. Pellets were resuspended in $1 \mathrm{ml}$ PBS without $\mathrm{CaCl}_{2}$ and $\mathrm{MgCl}_{2} \mathrm{pH} 7$, and $200 \mu \mathrm{l}$ were used for DNA extraction (corresponding to approximately $80 \mathrm{ml}$ of sweat) with QIAamp blood DNA mini-kit by Qiagen [41], (Fig. 1 left) remaining sample was used for RNA extraction. Concentration was measured using Qubits DNA HS assay kit (ThermoFisher). For buffer exchange and concentration Zymo DNA \& Clean-5 columns (Zymo Research) were used with modified protocol (5 volume of binding buffer and elution with $56{ }^{\circ} \mathrm{C}$ pre-heated $\mathrm{H}_{2} \mathrm{O}$ ). Samples from 3 individual donors (Table 1 top panel) were prepared in similar way. 


\section{A}

GO annotation : cell component

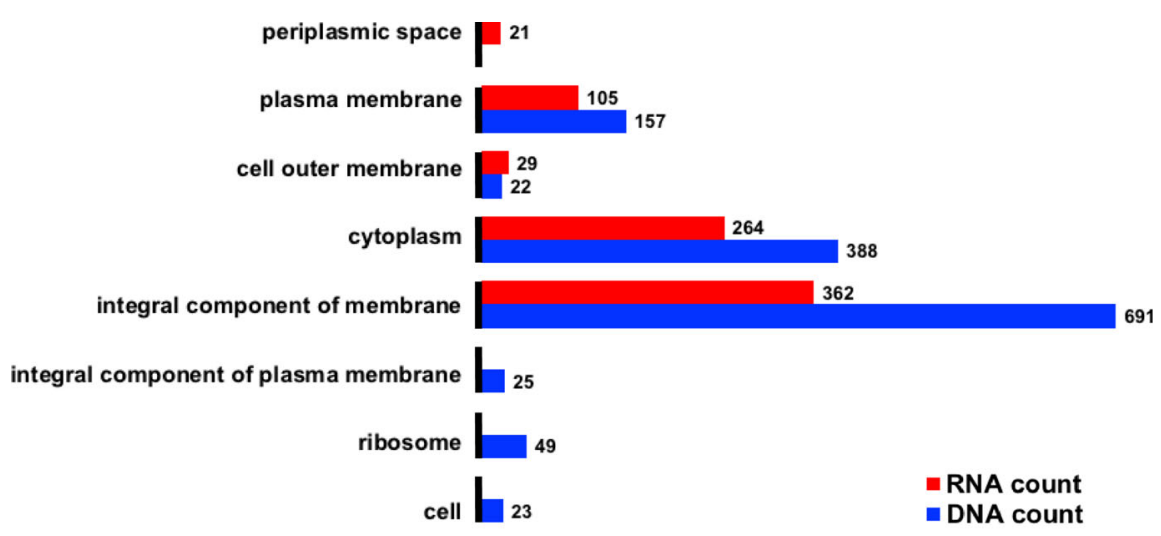

B

GO annotation : molecular function

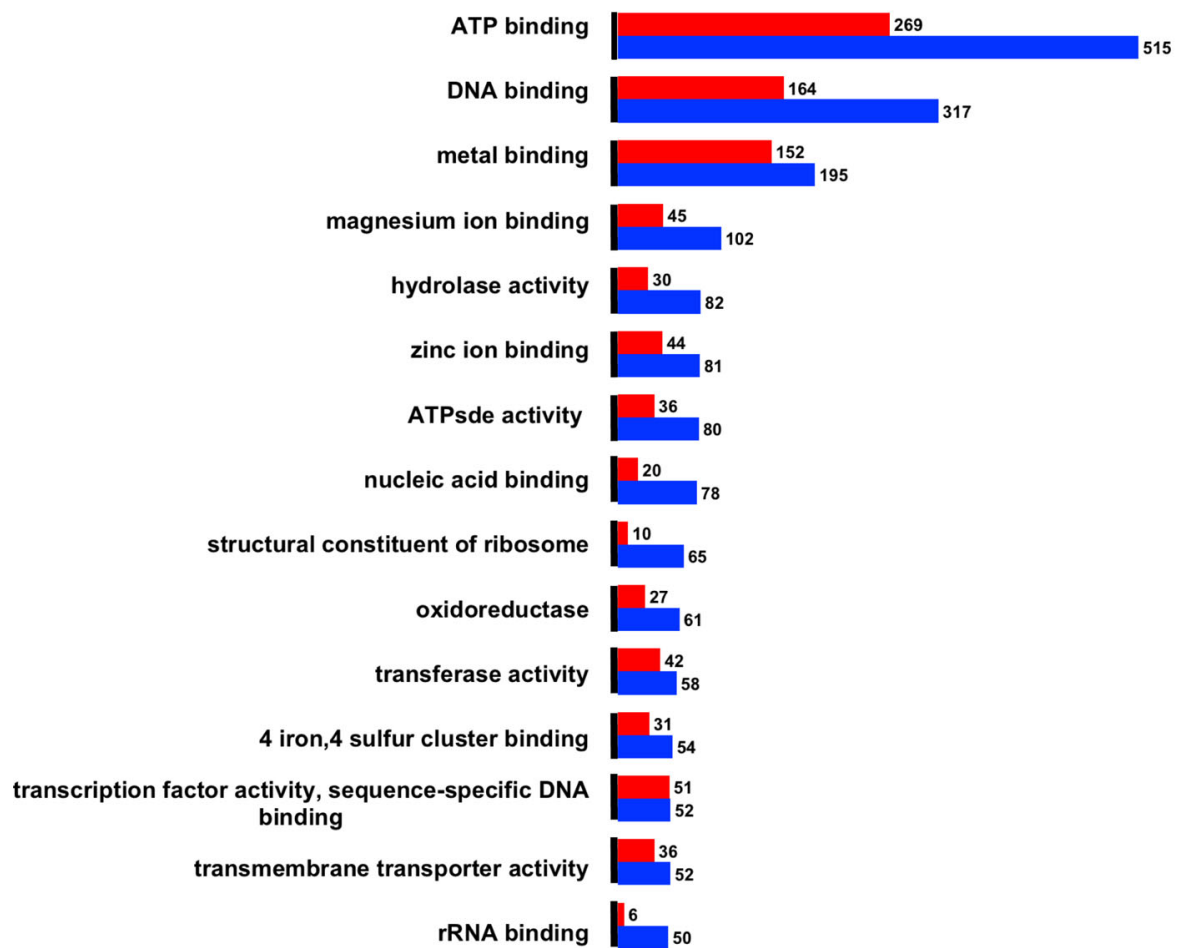

Fig. 12 bacterial GO annotations. Most represented GO annotation in bacterial genes identified A: most represented cell component. B: most represented molecular function with total count number indicated

One ng of DNA was used for PE library construction using Nextera XT library preparation kit (Illumina) according to manufacturer instructions. Libraries were run on NextSeq550 sequencer (Illumina) with 151 cycles in Biocenter Oulu sequencing core facility.

The remaining sample corresponding to $80 \%$ of the original sweat volume were used for RNA extraction with an ExoRNeasy kit (Qiagen) according to manufacturer's instructions.
Total RNA concentration was measured with Qubits RNA HS and profiled on Bioanalyzer 6000 Pico chips (Agilent). Pooled EV-enriched sweat RNA-seq RNA library was made using Ion Total RNA-Seq Kit v2 (Thermo Scientific) following instructions for small RNA libraries. In this case, purification beads were included in kit and used to remove adapter dimers. Final libraries were checked on a Bioanalyzer with High Sensitivity DNA kit 
Table 4 Human virus genes identified in sweat DNA

\begin{tabular}{|c|c|c|c|}
\hline Protein names & Gene names & Organism & Length \\
\hline Major capsid protein L1 & L1 & Gammapapillomavirus 9 & 521 \\
\hline Major capsid protein L1 & L1 gp7 & Human papillomavirus type 209 & 507 \\
\hline Major capsid protein L1 & L1 & Human papillomavirus & 514 \\
\hline Major capsid protein L1 & L1 & Gammapapillomavirus 9 & 513 \\
\hline Major capsid protein L1 & L1 & Human papillomavirus 204 & 508 \\
\hline Major capsid protein L1 & L1 & Human papillomavirus 202 & 528 \\
\hline Major capsid protein L1 & L1 & Human papillomavirus type 200 & 514 \\
\hline Major capsid protein L1 & L1 & Human papillomavirus type 49 & 509 \\
\hline Major capsid protein L1 & L1 & Gammapapillomavirus 22 & 517 \\
\hline Major capsid protein L1 & L1 & Gammapapillomavirus 12 & 507 \\
\hline Major capsid protein L1 & L1 & Human papillomavirus type 94 & 532 \\
\hline Major capsid protein L1 & L1 & Human papillomavirus type 8 & 514 \\
\hline Major capsid protein L1 & L1 & Human papillomavirus type 48 & 513 \\
\hline Major capsid protein L1 & L1 & Human papillomavirus 110 & 506 \\
\hline Major capsid protein L1 & L1 & Betapapillomavirus 2 & 508 \\
\hline Major capsid protein L1 & L1 & Human papillomavirus 174 & 507 \\
\hline Major capsid protein L1 & L1 & Human papillomavirus type 168 & 523 \\
\hline Major capsid protein L1 & L1 & Gammapapillomavirus 16 & 516 \\
\hline Major capsid protein L1 & L1 & Human papillomavirus type 137 & 516 \\
\hline Major capsid protein L1 & L1 & Gammapapillomavirus sp. & 517 \\
\hline Major capsid protein L1 & L1 & Human papillomavirus 138 & 514 \\
\hline Major capsid protein L1 & L1 & Human papillomavirus type 37 & 507 \\
\hline Major capsid protein L1 & L1 & Human papillomavirus type 94 & 532 \\
\hline Minor capsid protein L2 & L2 & Human papillomavirus 120 & 519 \\
\hline Minor capsid protein L2 & L2 & Betapapillomavirus 1 & 520 \\
\hline Minor capsid protein L2 & L2 & Human papillomavirus type 168 & 520 \\
\hline Minor capsid protein L2 & L2 & Gammapapillomavirus 16 & 507 \\
\hline Minor capsid protein L2 & L2 & Human papillomavirus 202 & 498 \\
\hline Minor capsid protein L2 & L2 & Human papillomavirus type 94 & 459 \\
\hline Minor capsid protein L2 & L2 & Betapapillomavirus 2 & 522 \\
\hline Minor capsid protein L2 & L2 & Human papillomavirus type 195 & 516 \\
\hline Minor capsid protein L2 & L2 & Human papillomavirus type 37 & 534 \\
\hline Minor capsid protein L2 & L2 & Gammapapillomavirus sp. & 518 \\
\hline Minor capsid protein L2 & L2 & Gammapapillomavirus 24 & 525 \\
\hline Minor capsid protein L2 & L2 & Human papillomavirus 204 & 503 \\
\hline Minor capsid protein L2 & L2 & uncultured Papillomavirus & 521 \\
\hline Minor capsid protein L2 & L2 & Gammapapillomavirus 12 & 521 \\
\hline Minor capsid protein L2 & L2 & Gammapapillomavirus 22 & 517 \\
\hline Minor capsid protein L2 & L2 & Human papillomavirus & 510 \\
\hline Minor capsid protein L2 & L2 & Human papillomavirus type 200 & 502 \\
\hline Minor capsid protein L2 & L2 & Betapapillomavirus 2 & 529 \\
\hline Minor capsid protein L2 & L2 & Human papillomavirus type 48 & 502 \\
\hline Minor capsid protein L2 & L2 & Human papillomavirus 110 & 537 \\
\hline Minor capsid protein L2 & L2 gp6 & Human papillomavirus type 209 & 519 \\
\hline
\end{tabular}


Table 4 Human virus genes identified in sweat DNA (Continued)

\begin{tabular}{|c|c|c|c|}
\hline Protein names & Gene names & Organism & Length \\
\hline Minor capsid protein L2 & L2 & Gammapapillomavirus 9 & 506 \\
\hline Minor capsid protein L2 & L2 & Human papillomavirus type 8 & 518 \\
\hline Protein E6 & E6 & Human papillomavirus type 94 & 148 \\
\hline Protein E6 & E6 & Human papillomavirus type 168 & 139 \\
\hline Protein E6 & E6 & Human papillomavirus type 8 & 155 \\
\hline Protein E6 & E6 & Human papillomavirus 202 & 143 \\
\hline Protein E6 & E6 & Human papillomavirus & 140 \\
\hline Protein E6 & E6 & Betapapillomavirus 2 & 141 \\
\hline Protein E6 & E6 & Human papillomavirus type 94 & 148 \\
\hline Protein E6 & E6 & Human papillomavirus type 137 & 142 \\
\hline Regulatory protein E2 & E2 & Human papillomavirus 157 & 400 \\
\hline Regulatory protein E2 & E2 HpV115gp4 & Human papillomavirus type 115 & 481 \\
\hline Regulatory protein E2 & E2 & Human papillomavirus type 94 & 378 \\
\hline Regulatory protein E2 & E2 & Human papillomavirus 204 & 388 \\
\hline Regulatory protein E2 & E2 & Human papillomavirus KC5 & 395 \\
\hline Regulatory protein E2 & E2 & Human papillomavirus 110 & 454 \\
\hline Regulatory protein E2 & E2 & Betapapillomavirus 2 & 459 \\
\hline Regulatory protein E2 & E2 & Human papillomavirus type 200 & 401 \\
\hline Regulatory protein E2 & E2 & Human papillomavirus & 398 \\
\hline Regulatory protein E2 & E2 & Human papillomavirus type 48 & 396 \\
\hline E4 & E4 & Human papillomavirus type 168 & 160 \\
\hline Replication protein E1 (EC 3.6.4.12) (ATP-dependent helicase E1) & E1 & Human papillomavirus 202 & 605 \\
\hline Replication protein E1 (EC 3.6.4.12) (ATP-dependent helicase E1) & E1 & Gammapapillomavirus 22 & 601 \\
\hline Replication protein E1 (EC 3.6.4.12) (ATP-dependent helicase E1) & E1 & Human papillomavirus 157 & 601 \\
\hline Replication protein E1 (EC 3.6.4.12) (ATP-dependent helicase E1) & E1 & Betapapillomavirus 1 & 620 \\
\hline Replication protein E1 (EC 3.6.4.12) (ATP-dependent helicase E1) & E1 & Human papillomavirus type 94 & 681 \\
\hline Replication protein E1 (EC 3.6.4.12) (ATP-dependent helicase E1) & E1 & Gammapapillomavirus 9 & 600 \\
\hline Replication protein E1 (EC 3.6.4.12) (ATP-dependent helicase E1) & E1 & Gammapapillomavirus sp. & 610 \\
\hline Replication protein E1 (EC 3.6.4.12) (ATP-dependent helicase E1) & E1 & Gammapapillomavirus sp. & 604 \\
\hline Replication protein E1 (EC 3.6.4.12) (ATP-dependent helicase E1) & E1 & Betapapillomavirus 2 & 605 \\
\hline Replication protein E1 (EC 3.6.4.12) (ATP-dependent helicase E1) & E1 & Human papillomavirus type 48 & 593 \\
\hline Replication protein E1 (EC 3.6.4.12) (ATP-dependent helicase E1) & E1 & Human papillomavirus type 200 & 598 \\
\hline Replication protein E1 (EC 3.6.4.12) (ATP-dependent helicase E1) & E1 & Human papillomavirus type 23 & 607 \\
\hline Replication protein E1 (EC 3.6.4.12) (ATP-dependent helicase E1) & E1 & Human papillomavirus 138 & 616 \\
\hline Replication protein E1 (EC 3.6.4.12) (ATP-dependent helicase E1) & E1 & Human papillomavirus 204 & 615 \\
\hline Replication protein E1 (EC 3.6.4.12) (ATP-dependent helicase E1) & E1 & Betapapillomavirus 2 & 605 \\
\hline Replication protein E1 (EC 3.6.4.12) (ATP-dependent helicase E1) & E1 & Human papillomavirus & 601 \\
\hline Replication protein E1 (EC 3.6.4.12) (ATP-dependent helicase E1) & E1 & Human papillomavirus type 22 & 608 \\
\hline Replication protein E1 (EC 3.6.4.12) (ATP-dependent helicase E1) & E1 & Human papillomavirus type 168 & 600 \\
\hline Replication protein E1 (EC 3.6.4.12) (ATP-dependent helicase E1) & E1 & Human papillomavirus 116 & 602 \\
\hline Replication protein E1 (EC 3.6.4.12) (ATP-dependent helicase E1) & E1 gp3 & Human papillomavirus type 209 & 607 \\
\hline Replication protein E1 (EC 3.6.4.12) (ATP-dependent helicase E1) & E1 & Human papillomavirus type 137 & 610 \\
\hline Replication protein E1 (EC 3.6.4.12) (ATP-dependent helicase E1) & E1 & Human papillomavirus & 600 \\
\hline Replication protein E1 (EC 3.6.4.12) (ATP-dependent helicase E1) & E1 & Human papillomavirus type 49 & 609 \\
\hline
\end{tabular}


Table 4 Human virus genes identified in sweat DNA (Continued)

\begin{tabular}{llll}
\hline Protein names & Gene names & Organism & Length \\
\hline Replication protein E1 (EC 3.6.4.12) (ATP-dependent helicase E1) & E1 & Human papillomavirus type 37 \\
Replication protein E1 (EC 3.6.4.12) (ATP-dependent helicase E1) & E1 & Human papillomavirus & 609 \\
Small T antigen & & MW polyomavirus & 206 \\
Small T antigen & & Merkel cell polyomavirus & 186 \\
ST (Small T antigen) & & Human polyomavirus 7 & 193 \\
Capsid protein VP1 & VP1 & MW polyomavirus & 403 \\
VP1 & VP1 & Human polyomavirus 7 & 380 \\
Uncharacterized protein UL126 & UL126 & Human cytomegalovirus (strain AD169) & 134
\end{tabular}

(Agilent). Sequencing of libraries was done with Ion PGM Hi-Q OT2 Template (200 bp protocol), Ion PGM Hi-Q Sequencing Kit and Ion PGM 318 chip kits (Thermo Scientific).

\section{Individual sweat collection and processing for nucleic acid processing and analysis}

Sweat was collected from the upper body, arms and torso using plastic raincoat (Transpen Oy, Kerava, FI) and disposable gloves VETbasic (15,364, Kerbl, Buchbach, Germany). If volunteers sweated heavily from their head, dripping sweat was collected in the head cover of the coat and pooled with the rest. Volunteers used exercise bike (ProSpinner spinning bike, Karhu) indoors for $30 \mathrm{~min}$ (Fig. 1 right). After exercise sweat was collected by cutting tip of gloves and cutting insert in ventral area to pipet fluid with sterile disposable pipet. Sweat was passed through $40 \mu \mathrm{m}$ strainer, then through $0,8 \mu \mathrm{m}$ filter (Millipore). If not immediately processed for nucleic acid extraction, filtered sweat was stored at $-20 \mathrm{oC}$ in sterile Falcon tubes.

Filtered sweat was concentrated on Centricon Plus-70 centrifugal filter (100 k cut-off), according to instructions by manufacturer. Concentrated sweat RNA was extracted using exoRNeasy kit (Qiagen).

RNA-seq libraries were made using NEBNext Small RNA kit (New England Biolabs). After 16 cycles of PCR amplification, Libraries were checked with Bioanalyzer using DNA 1000 chips (Agilent). Before size selection on pippin blue (Thermo Fisher) libraries were mixed in 2 pools according to DNA yield. Size selection was set to collect fragment from $145 \mathrm{bp}-200 \mathrm{bp}$. Size selected Pools were amplified an additional 5 cycles, purified wit PCR clean-up kit (Qiagen) and quantified by KAPA PCR kit (Roche). After dilution adjusting for library number in each pool, they were loaded on NextSeq550 (Illumina) and run 51 cycles.

\section{Bioinformatics analysis \\ DNA}

DNA fastQ files were checked with FastQC [42], merged using PEAR [43], merged and unmerged reads were aligned with BWA [44] against human genome HG38. Ensembl 94 annotation was used to intersect reads with functional elements. Coverage percentages for each chromosome was calculated as length of mapped reads per chromosome divided by length of chromosome.

\section{RNA}

Reads from different lanes were first merged into single fastq files and a QC was performed [42]. Then, low quality bases and adapter sequences were trimmed with trimmomatic [45] followed by another QC with FastQC. Trimmed reads were then mapped with Bowtie [46] against GtRNAdb high confidence tRNA sequences [47] and reads that map against tRNA sequences were also filtered out. The remaining reads were then mapped again with Bowtie against the human genome HG38, and further processed wit Cufflinks [48] and Cuffmerge to prepare a joint annotation file that contains then both known and novel genes. This annotation file as well as an annotation file for miRNAs from miRBase $[49,50]$ and Human piRNA sequence v2.0 from piRBase [51] was then used to quantify the expression with cufflinks and featureCounts [52]. For quantification, only exonic counts were taken into account. Alignment with STAR (Spliced Transcripts Alignment to a Reference ([53]) was done using Chipster at https://chipster.csc.fi/ [54].

Reads that could not be mapped against the HG38 genome were then de-novo assembled to contig level using MEGAHIT [55]. These contigs were then blasted against the NR database with DIAMOND [56], and for the identified proteins the corresponding IDs were extracted. Further, with Kraken [57] a taxonomic identification for the unmapped reads was performed and the results were visualized using Krona [58]. 
Table 5 Bacteriophages identified in sweat DNA

\begin{tabular}{|c|c|c|c|}
\hline Protein names & Gene names & Organism & Length \\
\hline aGPT-Pplase2 domain-containing protein & 3 ZEMANAR_3 & Mycobacterium phage Zemanar & 324 \\
\hline Amidase & ami & Propionibacterium phage PAS10 & 287 \\
\hline AP2/ERF domain-containing protein & AB9_137 & Acinetobacter phage vB_AbaM_B9 & 262 \\
\hline ATP-dependent helicase & 71 SEA_CATERPILLAR_71 & Arthrobacter phage Caterpillar & 411 \\
\hline ATP-dependent RNA helicase & & Pseudoalteromonas phage $\mathrm{H} 103$ & 599 \\
\hline ATPase_AAA_core domain-containing protein & BCP78_0083 & Bacillus phage $\mathrm{BCP} 78$ & 358 \\
\hline Baseplate J-like protein & 39 SEA_COLUCCI_39 & Arthrobacter phage Colucci & 373 \\
\hline Beta_helix domain-containing protein & Eldridge_088 & Bacillus phage Eldridge & 510 \\
\hline Capsid \& capsid maturation protease & 13 SEA_CATERPILLAR_13 & Arthrobacter phage Caterpillar & 717 \\
\hline Capsid and capsid maturation protease & 13 SEA_MEDIUMFRY_13 & Arthrobacter phage MediumFry & 717 \\
\hline Capsid and scaffold protein & & Propionibacterium phage PA1-14 & 186 \\
\hline Capsid maturation protease & 5 SEA_COLUCCI_5 & Arthrobacter phage Colucci & 649 \\
\hline Capsid maturation protease & SEA_C3PO_14 & Corynebacterium phage C3PO & 442 \\
\hline Capsid protein & & Staphylococcus phage philPLA-C1C & 291 \\
\hline Cas4 family exonuclease & SEA_NATOSALEDA_55 & Rhodococcus phage Natosaleda & 268 \\
\hline CMP deaminase & SEA_WEASELS2_199 & Rhodococcus phage Weasels2 & 118 \\
\hline Collagen-like protein & PHL308M00_19 & Propionibacterium phage PHL308M00 & 268 \\
\hline Collagen-like protein & PHL150M00_19 & Propionibacterium phage PHL150M00 & 268 \\
\hline DNA encapsidation protein & P9AB12kb_p002 & Pectobacterium phage DU_PP_III & 363 \\
\hline DNA helicase & 52 SEA_HOTFRIES_52 & Streptomyces phage HotFries & 390 \\
\hline DNA helicase & 93 PBI_COUNT_93 & Microbacterium phage Count & 435 \\
\hline DNA helicase & SEA_LUCKYBARNES_64 & Brevibacterium phage LuckyBarnes & 445 \\
\hline DNA helicase & SEA_MEAK_33 & Propionibacterium phage MEAK & 317 \\
\hline DNA methylase & 65 SEA_MOOMOO_65 & Mycobacterium phage MooMoo & 542 \\
\hline DNA methylase & 61 SEA_NERUJAY_61 & Mycobacterium phage Nerujay & 365 \\
\hline DNA methylase & SLPG_00003 & Salicola phage CGphi29 & 328 \\
\hline DNA methylase & FLORINDA_85 & Mycobacterium phage Florinda & 482 \\
\hline DNA methylase & 43 GALAXY_43 & Arthrobacter phage Galaxy & 439 \\
\hline DNA methylase & SEA_YASSJOHNNY_96 & Mycobacterium phage YassJohnny & 187 \\
\hline DNA methylase & SEA_MURICA_102 & Mycobacterium phage Murica & 602 \\
\hline DNA methylase & 61 PBI_SMEAGOL_61 & Mycobacterium phage Smeagol & 356 \\
\hline DNA methylase & 60 PBI_MUSEUM_60 & Mycobacterium virus Museum & 465 \\
\hline DNA polymerae/primase & NIKTSON_56 & Arthrobacter phage Niktson & 1314 \\
\hline DNA polymerase & P9AB12kb_p001 & Pectobacterium phage DU_PP_III & 690 \\
\hline DNA polymerase I & SEA_LUCKYBARNES_45 & Brevibacterium phage LuckyBarnes & 621 \\
\hline DNA polymerase III alpha subunit & SEA_DARWIN_47 & Corynebacterium phage Darwin & 1097 \\
\hline DNA polymerase III alpha subunit & SEA_C3PO_43 & Corynebacterium phage C3PO & 1097 \\
\hline DNA polymerase/primase & 54 SEA_CATERPILLAR_54 & Arthrobacter phage Caterpillar & 1309 \\
\hline DNA primase & SEA_LUCKYBARNES_63 & Brevibacterium phage LuckyBarnes & 804 \\
\hline DNA primase & 31 P141_31 & Propionibacterium phage P14 & 133 \\
\hline DNA primase & Salvo_71 & Xylella phage Salvo & 833 \\
\hline DNA primase & Iz_58 & Brucella phage $\mathrm{Iz}$ & 496 \\
\hline DNA primase/polymerase & SEA_C3PO_38 & Corynebacterium phage C3PO & 847 \\
\hline DNA primase/polymerase & 58 SEA_NIGHTMARE_58 & Arthrobacter phage Nightmare & 1312 \\
\hline
\end{tabular}


Table 5 Bacteriophages identified in sweat DNA (Continued)

\begin{tabular}{|c|c|c|c|}
\hline Protein names & Gene names & Organism & Length \\
\hline DNA single strand annealing protein Erf & uvFWCGRAMDCOMC203_065 & Freshwater phage uvFW-CGR-AMD-COM-C203 & 226 \\
\hline Endolysin & 20 P11_20 & Propionibacterium phage P1.1 & 284 \\
\hline Endonuclease & 45 SEA_THESTRAL_45 & Streptomyces phage Thestral & 400 \\
\hline Endonuclease VII & 18 SEA_PHISTORY_18 & Gordonia phage Phistory & 342 \\
\hline Exonuclease & WIZZO_26 & Propionibacterium phage Wizzo & 348 \\
\hline Exonuclease & MRAK_36 & Propionibacterium phage MrAK & 313 \\
\hline Exonuclease & & Pseudoalteromonas phage $\mathrm{H} 103$ & 292 \\
\hline Gp008 & Pepy6gene008 & Rhodococcus phage ReqiPepy6 & 118 \\
\hline Gp067 & Pepy6gene067 & Rhodococcus phage ReqiPepy6 & 226 \\
\hline Gp069 & Poco6gene069 & Rhodococcus phage ReqiPoco6 & 297 \\
\hline Gp077 & Pepy6gene077 & Rhodococcus phage ReqiPepy6 & 193 \\
\hline Gp14 & PaP-PAS50_gp14 & Propionibacterium phage PAS50 & 921 \\
\hline Gp16 & & Propionibacterium phage PA6 & 385 \\
\hline Gp48 & PaP-PAD20_gp48 & Propionibacterium phage PAD20 & 100 \\
\hline H_lectin domain-containing protein & PHL055N00_17 & Propionibacterium phage PHL055N00 & 276 \\
\hline Head protein & & Actinomyces virus Av1 & 455 \\
\hline Head-to-tail adaptor & 14 SEA_KYKAR_14 & Mycobacterium phage Kykar & 125 \\
\hline Head-to-tail connector & 12 BARRETLEMON_12 & Arthrobacter phage BarretLemon & 155 \\
\hline Head-to-tail connector protein & SEA_LILBANDIT_8 & Propionibacterium phage LilBandit & 115 \\
\hline Helix-turn-helix DNA binding domain protein & 132 PBI_COUNT_132 & Microbacterium phage Count & 927 \\
\hline Helix-turn-helix DNA binding domain protein & 78 SEA_LIBERTYBELL_78 & Streptomyces phage LibertyBell & 910 \\
\hline Helix-turn-helix DNA binding domain protein & PROCRASS1_25 & Propionibacterium phage Procrass1 & 106 \\
\hline Helix-turn-helix DNA binding domain protein & 76 PBI_CAMILLE_76 & Microbacterium phage Camille & 925 \\
\hline Helix-turn-helix DNA binding domain protein & 90 SEA_RAINYDAI_90 & Streptomyces phage Rainydai & 891 \\
\hline Helix-turn-helix DNA binding protein & 94 SEA_KEANEYLIN_94 & Arthrobacter phage KeaneyLin & 891 \\
\hline $\mathrm{HNH}$ endonuclease & SEA_SCAP1_2 & Streptomyces phage Scap1 & 135 \\
\hline HNH endonuclease & SEA_ATTOOMI_53 & Streptomyces phage Attoomi & 101 \\
\hline $\mathrm{HNH}$ endonuclease & SKKY_47 & Propionibacterium phage SKKY & 100 \\
\hline HNH endonuclease & 65 SEA_PHAYONCE_65 & Mycobacterium phage Phayonce & 196 \\
\hline HNH endonuclease & & Rhodococcus phage RRH1 & 91 \\
\hline HNH homing endonuclease & & Staphylococcus phage philPLA-C1C & 269 \\
\hline Holin & MRAK_21 & Propionibacterium phage MrAK & 133 \\
\hline Homing $\mathrm{HNH}$ endonuclase & endo IDF_12 & Enterococcus phage Idefix & 167 \\
\hline HTH DNA binding protein & 58 SEA_BARTHOLOMEW_58 & Mycobacterium phage Bartholomew & 331 \\
\hline J domain-containing protein & 75 SEA_FINCH_75 & Rhodococcus phage Finch & 194 \\
\hline Lower collar protein & & Staphylococcus phage St 134 & 282 \\
\hline LysM domain protein & 18 JAWNSKI_18 & Arthrobacter phage Jawnski & 221 \\
\hline Major capsid protein & 9 MARTHA_9 & Arthrobacter phage Martha & 295 \\
\hline Major capsid protein & gp79 E3_0790 & Rhodococcus phage E3 & 333 \\
\hline Major capsid subunit & 8 JAWNSKI_8 & Arthrobacter phage Jawnski & 297 \\
\hline Major head protein & PHL141N00_06 & Propionibacterium phage PHL141N00 & 315 \\
\hline Major head protein & mjh & Propionibacterium phage PAD21 & 314 \\
\hline Major head protein & PHL082M00_06 & Propionibacterium phage PHL082M00 & 323 \\
\hline Major tail protein & 16 GORDON_16 & Arthrobacter phage Gordon & 290 \\
\hline
\end{tabular}


Table 5 Bacteriophages identified in sweat DNA (Continued)

\begin{tabular}{|c|c|c|c|}
\hline Protein names & Gene names & Organism & Length \\
\hline Major tail protein & SEA_DRPARKER_11 & Propionibacterium phage DrParker & 213 \\
\hline Major tail protein & 14 SEA_RAINYDAI_14 & Streptomyces phage Rainydai & 294 \\
\hline Major tail protein & LAUCHELLY_11 & Propionibacterium phage Lauchelly & 212 \\
\hline Major tail protein & SEA_C3PO_23 & Corynebacterium phage C3PO & 220 \\
\hline Major tail sheath & 18 PRINCESSTRINA_18 & Arthrobacter phage PrincessTrina & 482 \\
\hline MazG-like nucleotide pyrophosphohydrolase & 41 PBI_PAJAZA_41 & Microbacterium phage Pajaza & 249 \\
\hline Membrane protein & 7 PBI_HYPERION_7 & Microbacterium phage Hyperion & 238 \\
\hline Membrane protein & 26 PBI_POUSHOU_26 & Corynebacterium phage Poushou & 152 \\
\hline Minor tail protein & SEA_SUPERNOVA_15 & Propionibacterium phage Supernova & 313 \\
\hline Minor tail protein & SEA_FRANZY_22 & Arthrobacter phage Franzy & 618 \\
\hline Minor tail protein & SEA_TIMINATOR_21 & Arthrobacter phage Timinator & 446 \\
\hline Minor tail protein & SEA_AQUARIUS_17 & Propionibacterium phage Aquarius & 272 \\
\hline Minor tail protein & MRAK_17 & Propionibacterium phage MrAK & 272 \\
\hline Minor tail protein & SEA_QUEENBEY_16 & Propionibacterium phage QueenBey & 385 \\
\hline Minor tail subunit & PHL301M00_15 & Propionibacterium phage PHL301M00 & 322 \\
\hline $\begin{array}{l}\mathrm{N} \text {-acetylmuramoyl-L-alanine amidase } \\
\text { domain-containing protein }\end{array}$ & & Propionibacterium phage pa33 & 286 \\
\hline $\begin{array}{l}\mathrm{N} \text {-acetylmuramoyl-L-alanine amidase } \\
\text { domain-containing protein }\end{array}$ & & Propionibacterium phage pa28 & 285 \\
\hline Nuclease & SEA_LUCKYBARNES_47 & Brevibacterium phage LuckyBarnes & 400 \\
\hline p55.1 & & Xanthomonas virus Xop411 & 189 \\
\hline PDDEXK_1 domain-containing protein & GMA2_62 & Gordonia phage GMA2 & 331 \\
\hline PDDEXK_1 domain-containing protein & 36P101A_36 & Propionibacterium phage P101A & 315 \\
\hline Pentapeptide repeat protein & SEP1_136 & Staphylococcus phage philBB-SEP1 & 209 \\
\hline Peptidoglycan hydrolase & SEA_BRENT_19 & Arthrobacter phage Brent & 448 \\
\hline phage terminase, large subunit & g04 & Yersinia phage fEV-1 & 462 \\
\hline POLAC domain-containing protein & GMA2_66 & Gordonia phage GMA2 & 594 \\
\hline Portal & 3 P141_3 & Propionibacterium phage P14 & 441 \\
\hline Portal protein & SEA_DRGREY_12 & Streptomyces phage DrGrey & 450 \\
\hline Portal protein & 4 SEA_COLUCCI_4 & Arthrobacter phage Colucci & 476 \\
\hline Portal protein & KEIKI_3 & Propionibacterium phage Keiki & 441 \\
\hline Portal protein & SEA_DRPARKER_3 & Propionibacterium phage DrParker & 441 \\
\hline Portal protein & PHL092M00_03 & Propionibacterium phage PHL092M00 & 441 \\
\hline Portal protein & ArV1_002 & Arthrobacter phage vB_ArtM-ArV1 & 476 \\
\hline Prim-Pol domain-containing protein & & Pseudoalteromonas phage $\mathrm{H} 103$ & 761 \\
\hline Putative amidase & PHL060L00_20 & Propionibacterium phage PHL060L00 & 288 \\
\hline Putative bifunctional DNA primase/polymerase & M22_064 & Idiomarinaceae phage Phi1M2-2 & 754 \\
\hline Putative bifunctional DNA primase/polymerase & S708_57 & Brucella phage 5708 & 780 \\
\hline Putative capsid & 6 P1001_6 & Propionibacterium phage P100_1 & 314 \\
\hline Putative dCTP deaminase & PhAPEC7_24 & Escherichia phage vB_EcoP_PhAPEC7 & 168 \\
\hline Putative DNA helicase & GMA2_64 & Gordonia phage GMA2 & 654 \\
\hline Putative DNA helicase & PHL111M01_33 & Propionibacterium phage PHL111M01 & 317 \\
\hline Putative DNA helicase & PAC5_34 & Propionibacterium phage PAC5 & 287 \\
\hline Putative DNA methyltransferase & 55 BRUJITA_55 & Mycobacterium virus Brujita & 216 \\
\hline Putative DNA primase & & Propionibacterium phage PacnesP1 & 241 \\
\hline
\end{tabular}


Table 5 Bacteriophages identified in sweat DNA (Continued)

\begin{tabular}{|c|c|c|c|}
\hline Protein names & Gene names & Organism & Length \\
\hline Putative DNA primase & PHL111M01_30 & Propionibacterium phage PHL111M01 & 223 \\
\hline Putative DNA primase & PHL085N00_30 & Propionibacterium phage PHL085N00 & 241 \\
\hline Putative DNA primase & PHL111M01_31 & Propionibacterium phage PHL111M01 & 133 \\
\hline Putative endolysin & PHL179M00_20 & Propionibacterium phage PHL179M00 & 296 \\
\hline Putative exonuclease & $753 \_41$ & uncultured Caudovirales phage & 281 \\
\hline Putative helicase & Tb_ORF45 & Brucella phage $\mathrm{Tb}$ & 577 \\
\hline Putative major head protein & PHL037M02_06 & Propionibacterium phage PHL037M02 & 316 \\
\hline Putative major tail protein & GMA2_25 & Gordonia phage GMA2 & 139 \\
\hline Putative membrane protein & Twillingate_011 & Staphylococcus phage Twillingate & 41 \\
\hline $\begin{array}{l}\text { Putative phosphoribosyl-ATP } \\
\text { pyrophosphohydrolase }\end{array}$ & SmphiM6_41 & Sinorhizobium phage phiM6 & 129 \\
\hline Putative portal & 3 P100D_3 & Propionibacterium phage P100D & 441 \\
\hline Putative portal protein & PAC4_3 & Propionibacterium phage PAC4 & 406 \\
\hline Putative protease & PHL025M00_16 & Propionibacterium phage PHL025M00 & 385 \\
\hline Putative protease & PHL082M03_16 & Propionibacterium phage PHL082M03 & 385 \\
\hline Putative recA-like NTPase & vBEcoSSa179w3YLVW_00039 & Escherichia phage vB_EcoS Sa179lw & 274 \\
\hline Putative recA-like NTPase & Sf11_gp7 & Shigella phage Sf11 SMD-2017 & 276 \\
\hline Putative sigma factor & PHL082M03_23 & Propionibacterium phage PHL082M03 & 130 \\
\hline Putative structural protein & GMA2_16 & Gordonia phage GMA2 & 554 \\
\hline Putative structural protein & GMA2_9 & Gordonia phage GMA2 & 584 \\
\hline Putative tape measure & 14 P104A_14 & Propionibacterium phage P104A & 921 \\
\hline Putative tape measure & 14 ATCC29399BT_14 & Propionibacterium phage ATCC29399B_T & 921 \\
\hline Putative tape measure protein & PHL112N00_14 & Propionibacterium phage PHL112N00 & 921 \\
\hline Putative terminase & GMA2_1 & Gordonia phage GMA2 & 559 \\
\hline Putative terminase & PHL111M01_02 & Propionibacterium phage PHL111M01 & 503 \\
\hline Putative terminase large subunit & 2P104A_2 & Propionibacterium phage P104A & 503 \\
\hline Putative terminase large subunit & ABP12_00064 & Acinetobacter phage WCHABP12 & 433 \\
\hline Putative type III restriction endonuclease & p11sa141_49 & Brucella phage 11sa_141 & 141 \\
\hline Putative VRR-DNA nuclease & M22_057 & Idiomarinaceae phage Phi1M2-2 & 136 \\
\hline Twillingate_149 & & Staphylococcus phage Twillingate & 409 \\
\hline $\begin{array}{l}\text { Ribonucleoside-diphosphate reductase large } \\
\text { subunit (EC 1.17.4.1) }\end{array}$ & vBPaeSS218_00016 & Pseudomonas phage vB_PaeS_S218 & 607 \\
\hline Ribonucleotide reductase & SEA_C3PO_3 & Corynebacterium phage C3PO & 171 \\
\hline Ribonucleotide reductase & SEA_DARWIN_74 & Corynebacterium phage Darwin & 648 \\
\hline Ribonucleotide reductase large subunit & phiAbaA1_082 & Acinetobacter phage vB_AbaM_phiAbaA1 & 968 \\
\hline $\begin{array}{l}\text { Ribonucleotide reductase large subunit } \\
\text { (EC 1.17.4.1) }\end{array}$ & SEP1_061 & Staphylococcus phage philBB-SEP1 & 705 \\
\hline RIIA-like protein & 153 SEA_ANNADREAMY_153 & Streptomyces phage Annadreamy & 639 \\
\hline RIIB-like protein & 164 SEA_COMRADE_164 & Streptomyces phage Comrade & 336 \\
\hline RIIB-like protein & SEA_MILDRED21_228 & Streptomyces phage Mildred21 & 326 \\
\hline RNA-binding protein & & Streptomyces phage BRock & 523 \\
\hline Scaffold protein & PHL179M00_05 & Propionibacterium phage PHL179M00 & 184 \\
\hline Scaffolding protein & SEA_LILBANDIT_5 & Propionibacterium phage LilBandit & 184 \\
\hline Scaffolding protein & MOYASHI_5 & Propionibacterium phage Moyashi & 184 \\
\hline Secreted transglycosylase & Quidividi_034 & Staphylococcus phage Quidividi & 220 \\
\hline
\end{tabular}


Table 5 Bacteriophages identified in sweat DNA (Continued)

\begin{tabular}{|c|c|c|c|}
\hline Protein names & Gene names & Organism & Length \\
\hline SF4 helicase domain-containing protein & & Propionibacterium phage pa28 & 287 \\
\hline Structural protein & Pepy6gene012 & Rhodococcus phage ReqiPepy6 & 115 \\
\hline Structural protein & AB9_053 & Acinetobacter phage vB_AbaM_B9 & 178 \\
\hline Tail assembly chaperone & SEA_C3PO_27 & Corynebacterium phage C3PO & 273 \\
\hline Tail assembly chaperone & AB9_056 & Acinetobacter phage vB_AbaM_B9 & 131 \\
\hline Tail assembly chaperone & SEA_LEVIOSA_13 & Propionibacterium phage Leviosa & 227 \\
\hline Tail length tape-measure protein & & Propionibacterium phage pa33 & 921 \\
\hline Tail length tape-measure protein & & Propionibacterium phage pa63 & 921 \\
\hline Tail lysin & SEP1_028 & Staphylococcus phage philBB-SEP1 & 1401 \\
\hline Tail lysozyme & 30 TAEYOUNG_30 & Arthrobacter phage TaeYoung & 110 \\
\hline Tail protein & 32 BARRETLEMON_32 & Arthrobacter phage BarretLemon & 427 \\
\hline Tail protein & 19 JAWNSKI_19 & Arthrobacter phage Jawnski & 448 \\
\hline Tail protein & & Moraxella phage Mcat20 & 1460 \\
\hline Tail protein & & Staphylococcus phage philPLA-C1C & 1151 \\
\hline Tail protein & 27 PRINCESSTRINA_27 & Arthrobacter phage PrincessTrina & 645 \\
\hline Tail protein & 35 KELLEZIO_35 & Arthrobacter phage KellEzio & 1704 \\
\hline Tail protein & vB_RpoS-V16_51 & Ruegeria phage vB_RpoS-V16 & 1614 \\
\hline Tail protein & & Actinomyces virus Av1 & 731 \\
\hline Tail sheath & 14 JAWNSKI_14 & Arthrobacter phage Jawnski & 482 \\
\hline Tail sheath & 15 MARTHA_15 & Arthrobacter phage Martha & 482 \\
\hline Tail sheath protein & AB9_051 & Acinetobacter phage vB_AbaM_B9 & 381 \\
\hline Tail sheath protein & SEA_CHOCOLAT_18 & Arthrobacter phage Chocolat & 482 \\
\hline Tail spike protein & CPT_Mater149 & Bacillus phage Mater & 663 \\
\hline Tail spike protein & Eldridge_087 & Bacillus phage Eldridge & 663 \\
\hline Tail-like protein & Shpa_19 & Paracoccus phage Shpa & 1072 \\
\hline Tape measure protein & PHL141N00_14 & Propionibacterium phage PHL141N00 & 921 \\
\hline Tape measure protein & PHL067M09_14 & Propionibacterium phage PHL067M09 & 921 \\
\hline Tape measure protein & SEA_LUCY_14 & Arthrobacter phage Lucy & 853 \\
\hline Tape measure protein & PROCRASS1_14 & Propionibacterium phage Procrass1 & 921 \\
\hline Tape measure protein & NIKTSON_26 & Arthrobacter phage Niktson & 1529 \\
\hline Tape measure protein & AB9_058 & Acinetobacter phage vB_AbaM_B9 & 681 \\
\hline Tape measure protein & 22 SEA_CHEESY_22 & Arthrobacter phage Cheesy & 1492 \\
\hline Tape measure protein & Gsput1_18 & Gordonia phage Gsput1 & 1431 \\
\hline Tape measure protein & PHL082M02_14 & Propionibacterium phage PHL082M02 & 921 \\
\hline Tape measure protein & KEIKI_14 & Propionibacterium phage Keiki & 921 \\
\hline Tape measure protein & 17 SEA_FROKOSTDAME_17 & Gordonia phage Frokostdame & 1824 \\
\hline Tapemeasure protein & SEA_AQUARIUS_14 & Propionibacterium phage Aquarius & 921 \\
\hline Terminase & PHL009M11_02 & Propionibacterium phage PHL009M11 & 503 \\
\hline Terminase large subunit & 6 SEA_HOTFRIES_6 & Streptomyces phage HotFries & 581 \\
\hline Terminase large subunit & SEA_TIMINATOR_2 & Arthrobacter phage Timinator & 489 \\
\hline Terminase large subunit & BiPBO1_02 & Brucella phage BiPBO1 & 562 \\
\hline Terminase large subunit & KEIKI_2 & Propionibacterium phage Keiki & 503 \\
\hline Terminase large subunit & 8 CIRCUM_8 & Arthrobacter phage Circum & 584 \\
\hline Terminase large subunit & MRAK_2 & Propionibacterium phage MrAK & 503 \\
\hline
\end{tabular}


Table 5 Bacteriophages identified in sweat DNA (Continued)

\begin{tabular}{|c|c|c|c|}
\hline Protein names & Gene names & Organism & Length \\
\hline Terminase small subunit & BiPBO1_01 & Brucella phage BiPBO1 & 133 \\
\hline Terminase small subunit & 3 SEA_MEMENTOMORI_3 & Microbacterium phage MementoMori & 194 \\
\hline Terminase small subunit & SEA_C3PO_1 & Corynebacterium phage C3PO & 174 \\
\hline Thioredoxin & SEA_DARWIN_54 & Corynebacterium phage Darwin & 98 \\
\hline Thymidylate synthase & SEA_ZION_9 & Corynebacterium phage Zion & 257 \\
\hline Thymidylate synthase & SEA_LUCKYBARNES_41 & Brevibacterium phage LuckyBarnes & 517 \\
\hline Thymidylate synthase & CB7_206 & Pectobacterium phage vB_PatM_CB7 & 226 \\
\hline Thymidylate synthase & 109 PBI_COUNT_109 & Microbacterium phage Count & 232 \\
\hline Toprim domain-containing protein & 30 P100D_30 & Propionibacterium phage P100D & 223 \\
\hline Transposase & SEP1_056 & Staphylococcus phage philBB-SEP1 & 369 \\
\hline $\begin{array}{l}\text { Tryptophan synthase beta } \\
\text { superfamily protein }\end{array}$ & 2 SEA_ALANGRANT_2 & Mycobacterium phage AlanGrant & 289 \\
\hline
\end{tabular}

\section{GO analysis}

List of genes with FPKM values 25 or over were put into geneontology.org for enrichment analysis ( [59], the gene ontology consortium 2019) using Fisher's exact test with Bonferroni correction for multiple testing and GO annotation with enrichment value 4 or over were visualized using REVIGO [60], dispensable GO terms were omitted.

\section{miRNA QPCR}

$1,5 \mathrm{ng}$ of RNA was used for cDNA synthesis using miRCURY LNA RT-PCR kit (Qiagen).

Following LNA primers were used for QPCR using SYBR Green III master mix (Agilent) miRCURY LNA miRNA QPCR Assay: miR24-3p (YP00204260), miR99a5p (YP00204521), miR193 (YP00204226), miR-21-5p (MS00009079), miR-26a-5p (MS00029239), miR320b (MIMAT0005792), U6 snRNA (X59362).

\section{RT-PCR}

CDNA was made from 5 ng of RNA using VILO or Maxima $\mathrm{H}$ - first strand cDNA synthesis kit with DS DNAse (Thermo Fisher). After 1/2 dilution cDNA was amplified using AmpliTaq Gold and specific primers:

\begin{tabular}{lll}
\hline Gene & forward primer & reverse primer \\
\hline 14-3-3 Protein Epsilon & ACAGAACTCCACCAA & ATTCTGCTCTTCACCG \\
(YWHAE) & CGCA & TCACC \\
Ferritin Light Chain & GGACCCCCATCTCT & AGTCGTGCTTGAGA \\
(FTL) & GTGACT & GTGAGC \\
\hline
\end{tabular}

PCR conditions: 95oC $5 \mathrm{~min}, 60 \mathrm{oC} 20 \mathrm{~s}, 72 \mathrm{oC} 20 \mathrm{~s}$, $950 C 20$ s, 40 cycles. Products were analyzed on $2 \%$ agarose gel, stained with midori green and photographed. PCR products were purified using Qiagen minElute columns (Qiagen) and sequenced in Biocenter Oulu sequencing core facility using capillary sequencing with BigDyeTERminator v1.1 cycle sequencing (ABI) and ABI3500xL Genetic Analyzer.

\section{Electron microscopy}

The immunoelectron microscopy was performed using biotinylated anti-CD9 antibody as a primary antibody at a 1:10 dilution. Vesicles were deposited on a Formvar carbonated grid (glow-discharged). The grids were incubated in blocking serum (1\% BSA (bovine serum albumin) in PBS). Afterwards, the grids were incubated for 20 mins with the primary anti-CD9 antibody (Miltenyi Biotec), followed by the secondary anti-biotin antibody for $20 \mathrm{~min}$ and finally the protein A-gold complex (PAG $10 \mathrm{~nm}$ ) for $20 \mathrm{~min}$. Samples after immunonegative staining as well as after negative staining with $2 \%$ uranyl acetate were examined using a Tecnai G2 Spirit transmission electron microscope (FEI, Eindhoven, The Netherlands) and images were captured with a chargecoupled device camera (Quemesa, Olympus Soft Imaging Solutions GMBH, Münster, Germany). Anti-CD63 antibody for immuno-TEM was used at dilution 1:50 (Abcam ab193349) and polyclonal anti-Glypican 1 antibody (PA5-28055, ThermoFisher) at dilution 1:100.

For preparing plastic sections concentrated sweat was filtered on 0.45 um Minisart filter (Sartorius), then sweat EVs were stained with CellVue Claret Far Fluorescent Cell Linker Midi Kit (MIDCLARET-1KT) according to manufacturer's instructions. After staining, samples were centrifuged for $4-6 \mathrm{~h}$ at $120 \mathrm{~K} \mathrm{rpm} \mathrm{k}$-factor $=16$ at $4{ }^{\circ} \mathrm{C}$ Beckman TLA 120.2). Supernatants were removed, pellets fixed and plastic embedded in Biocenter Oulu electron microscopy core facility. Thin sections were observed with Tecnai G2 Spirit electron microscope. 


\section{Western blotting}

EV samples were diluted in $5 \mathrm{X}$ Laemmli loading buffer and proteins were separated on 10\% SDS PAGE gel, then transferred to nitrocellulose membrane. Anti-CD63 (Abcam Ab193349; 1:500 and Santa Cruz H-193, sc-15, 362; 1:1000 dilutions), GM130 (Cell Signaling Technology, \#12480; 1:1000) and Ago2 (Abcam ab32381; 1:1000) antibodies were used for detection.

\section{Nanoparticle tracking analysis}

Nanoparticle tracking analysis (NTA) was performed using a NanoSight NS300 (NanoSight Ltd., Amesbury, UK) equipped with a $405 \mathrm{~nm}$ laser. At least three $40 \mathrm{~s}$ videos were recorded of each sample with camera level and detection threshold set up at 13. Temperature was monitored throughout the measurements. Videos recorded for each sample were analyzed with NTA software version 3.1. (build 3.1.46) to determine the concentration and size of measured particles with corresponding standard error. For analysis, auto settings were used for blur, minimum track length and minimum expected particle size. Double distilled $\mathrm{H}_{2} \mathrm{O}$ was used to dilute the starting material.

\section{Abbreviations}

EV: Extracellular vesicle; NGS: Next-generation sequencing; TEM: Transmission electron microscopy; FPKM: Fragments per kilobase per million reads mapped; STAR: Spliced Transcripts Alignment to a Reference; RT-PCR: Reverse transcription polymerase reaction; qPCR: quantitative polymerase chain reaction

\section{Supplementary Information}

The online version contains supplementary material available at https://doi. org/10.1186/s12864-021-07733-9.

Additional file 1: Supplementary Figure 1. Bioanalyzer profile of RNA from individual samples of EV-enriched sweat. RNA analysis profiles for all subjects 1 ul of RNA was run on Agilent pic0600 chips. Supplementary Figure 2. piRNA in individual samples. piRNA percentages in 20 individual samples, below table with normalized value for each sample. Supplementary Figure 3. TEM images, negative staining of EV-enriched sweat. Negative control image (PBS wash of collection glove processed as sweat samples), images of ExoEasy processed sweat from 4 different volunteers. Supplementary Figure 4. Nanoparticle Tracking analysis from Exoeasy prepared sweat, summary of 5 different isolations. Supplementary Figure 5. Western blots with protein from negative control (collection glove washed in PBS and processed with exoEasy as sweat), unbound material from ExoEasy column (flowthrough), ExoEasy eluted fraction (EVenriched), and concentrated sweat (cut-off $100 \mathrm{kDa}$ ), were stained with anti-CD63 antibody (EV marker) and antibodies against non-EV markers Ago2 and GM130. A: membrane B: the same membrane probed with anti-CD63 antibdy. Fluorescent images were inverted, contrast and brightness adjusted to make bands visible. C: the same membrane probed with anti-Ago2 antibody. D: membrane E: the same membrane probed with anti-GM130 antibody. Supplementary Figure 6. Western blot, whole membrane from Fig. 4E. EV-enriched (ExoEasy isolation) sweat samples from three individuals were loaded (marked 2, 3, and 32). Region cropped is marked by the black frame. Original fluorescence image was inverted, then brightness and contrast were increased to make bands more visible. Supplementary Figure 7. Whole $2 \%$ agarose gel images for Fig. 10. Individual samples' RNA was reverse transcribed and amplified with primers designed to amplify mRNA across exon-exon junctions. FTL band was cropped form each individual gel, cropped image is marked in blue box, YWHAE band was cropped from individual gels as indicated by red boxes

Additional file 2: Supplementary Table 1. Transcripts identified in at least 18 samples.

Additional file 3: Supplementary Table 2. Comparison of top $1 \%$ RNA identified in Illumina and lon Torrent.

\section{Acknowledgements}

We thank Hannu Kaikkonen and Prof. Raija Korpelainen form Oulu Deaconess Institute Sport Clinic for their invaluable help in setting up the sweat collection method for this project, Marko Suokas and docent Katri Pylkäs (BCO sequencing core facility), Hannele Härkman, Paula Haipus, Getnet Midekassa, Muhammad Umair Anwar, Emma Karjalainen, Johanna KekolahtiLiias, Meeri Otsukka, Leena Keskitalo. Abishek Sharma for recruiting volunteers. NGS was done at Biocenter Oulu, Sequencing core facility. CSC - IT Center for Science, Finland and CSC - TIETEEN TIETOTEKNIIKAN KESKUS OY/ IT Center for Science LTD for computational resources. We are grateful to the volunteers who donated sweat.

\section{Authors' contributions}

Study design $\left(G B, J H, S V^{1}\right)$, experimental design $(G B, A S)$, sweat collection and processing (GB, AS, PS, AZ, TN, PS $\left.{ }^{4}\right)$, EV preparation (GB, TN, LR, PS, PS ${ }^{4}$ $\left.P S^{1}, A Z\right), D N A$ and $R N A$ preparation $\left(G B, P S^{1}\right)$, library preparation and RNA analysis $(G B)$, bioinformatics $\left(G B, D F, S V^{2}\right)$, imaging (AS, IM, MK), data analysis and manuscript writing $\left(G B, S K, L R, A S, S V^{1}\right)$. All authors have read and approved the manuscript.

\section{Funding}

These studies were supported by the following research grants: Centre of Excellence grant (2012-2017 251314), the European Community's Seventh Framework Programme (FP7/2007-2013; grant FP7-HEALTH-F5), HILLA, Business Finland (BioRealHealth), Academy of Finland Biofuture2025, and European Union Regional Development Fund (Printocent10). Part of the infrastructure was supported by the Academy of Finland Research Infrastructure Grant (PII-FIRI, Grant no. 32020).

\section{Availability of data and materials}

The RNA and DNA data described in this paper will be available from the European Nucleotide Archive (EMBL-EBI) under accession number PRJEB40112 https://www.ebi.ac.uk/ena/browser/home.

\section{Declarations}

Ethics approval and consent to participate

These studies were performed according to the Declaration of Helsinki on research involving humans. The study protocol named RUBY was approved by the Ethical Committee at the Northern Ostrobothnia Hospital District in Oulu under Study Diary Number 110/2015.

Participants in the study were given information about the study and signed informed consent forms approved by the ethics committee.

\section{Consent for publication}

No pictures of individuals or other identifying material were recorded in this study.

\section{Competing interests}

The authors declare no competing interests.

\section{Author details}

${ }^{1}$ Faculty of Biochemistry and Molecular Medicine, Disease Networks Research Unit, Laboratory of Developmental Biology, Kvantum Institute, Infotech Oulu, University of Oulu, 90014 University of Oulu, Oulu, Finland. ${ }^{2}$ Production Systems, Natural Resources Institute Finland (LUKE), 31600 Jokioinen, Finland. ${ }^{3}$ Present Address: Finnadvance, Aapistie 5, 90220 Oulu, Finland. ${ }^{4}$ Biosensors, VIT, Technical Research Center of Finland Ltd, Kaitoväylä 1, 90570 Oulu, Finland. 
Received: 18 December 2020 Accepted: 17 May 2021 Published online: 09 June 2021

\section{References}

1. Chen X, Gasecka P, Formanek F, Galey J-B, Rigneault H. In vivo single human sweat gland activity monitoring using coherent anti-stokes Raman scattering and two-photon excited autofluorescence microscopy. $\mathrm{Br}\rfloor$ Dermatol. 2016;174(4):803-12. https://doi.org/10.1111/bjd.14292.

2. Cui $Y$, Duan W, Jin $Y$, Wo F, Xi F, Wu J. Ratiometric fluorescent Nanohybrid for noninvasive and visual monitoring of sweat glucose. ACS Sens. $2020 \mathrm{Jul}$ 24;5(7):2096-105. https://doi.org/10.1021/acssensors.0c00718.

3. Lee H, Song C, Hong YS, Kim MS, Cho HR, Kang T, et al. Wearable/ disposable sweat-based glucose monitoring device with multistage transdermal drug delivery module. Sci Adv. 2017 Mar;3(3):e1601314. https:// doi.org/10.1126/sciadv.1601314

4. Moyer J, Wilson D, Finkelshtein I, Wong B, Potts R. Correlation between sweat glucose and blood glucose in subjects with diabetes. Diabetes Technol Ther. 2012 May;14(5):398-402. https://doi.org/10.1089/dia.2011.0262.

5. Raiszadeh MM, Ross MM, Russo PS, Schaepper MA, Zhou W, Deng J, et al. Proteomic analysis of eccrine sweat: implications for the discovery of schizophrenia biomarker proteins. J Proteome Res. 2012 Apr 6;11(4):212739. https://doi.org/10.1021/pr2007957.

6. Adewole OO, Erhabor GE, Adewole TO, Ojo AO, Oshokoya H, Wolfe LM, et al. Proteomic profiling of eccrine sweat reveals its potential as a diagnostic biofluid for active tuberculosis. Proteomics Clin Appl. 2016;10(5): 547-53. https://doi.org/10.1002/prca.201500071.

7. Byrd AL, Belkaid Y, Segre JA. The human skin microbiome. Nat Rev Microbiol. 2018;16(3):143-55. https://doi.org/10.1038/nrmicro.2017.157.

8. Ortiz-Movilla N, Lázaro P, Rodríguez-Iñigo E, Bartolomé J, Longo I, Lecona M, et al. Hepatitis $C$ virus replicates in sweat glands and is released into sweat in patients with chronic hepatitis C. J Med Virol. 2002 Dec;68(4):529-36. https://doi.org/10.1002/jmv.10238.

9. Akutsu T, Watanabe K, Takamura A, Sakurada K. Evaluation of skin- or sweatcharacteristic mRNAs for inferring the human origin of touched contact traces. Leg Med Tokyo Jpn. 2018;33:36-41. https://doi.org/10.1016/j.lega Imed.2018.05.003.

10. Hair ME, Mathis Al, Brunelle EK, Halámková L, Halámek J. Metabolite Biometrics for the Differentiation of Individuals. Anal Chem. 2018;90(8):5322-8.

11. Hulstaert E, Morlion A, Cobos FA, Verniers K, Nuytens J, Eynde EV, et al. Charting extracellular transcriptomes in The Human Biofluid RNA Atlas. bioRxiv. 2020;4:823369.

12. Zhang C, Liu P. The lipid droplet: a conserved cellular organelle. Protein Cell. 2017;8(11):796-800. https://doi.org/10.1007/s13238-017-0467-6.

13. Baker LB. Physiology of sweat gland function: the roles of sweating and sweat composition in human health. Temperature. 2019 Jul 3;6(3):211-59. https://doi.org/10.1080/23328940.2019.1632145.

14. Fischer H, Fumicz J, Rossiter H, Napirei M, Buchberger M, Tschachler E, et al. Holocrine secretion of sebum is a unique DNase2-dependent mode of programmed cell death. J Invest Dermatol. 2017 Mar;137(3):587-94. https:// doi.org/10.1016/j.jid.2016.10.017.

15. Schaumburg-Lever G, Lever WF. Secretion from human apocrine glands: an Electron microscopic study. J Invest Dermatol. 1975 Jan;64(1):38-41. https:// doi.org/10.1111/1523-1747.ep12540893.

16. Wu C-X, Liu Z-F. Proteomic profiling of sweat exosome suggests its involvement in skin immunity. J Invest Dermatol. 2018;138(1):89-97. https:// doi.org/10.1016/j.jid.2017.05.040.

17. Karvinen SM, Sievänen TO, Karppinen JE, Hautasaari PT, Bart G, Samoylenko $A$, et al. MicroRNAs in extracellular vesicles in sweat change in response to endurance exercise. Front Physiol. 2020;11:676. https://doi.org/10.3389/ fphys.2020.00676.

18. Li J, Guan X, Fan Z, Ching L-M, Li Y, Wang X, et al. Non-invasive biomarkers for early detection of breast Cancer. Cancers. 2020 Sep 27;12(10):2767. https://doi.org/10.3390/cancers12102767.

19. Enderle D, Spiel A, Coticchia CM, Berghoff E, Mueller R, Schlumpberger M, et al. Characterization of RNA from Exosomes and Other Extracellular Vesicles Isolated by a Novel Spin Column-Based Method. Bouma GJ, editor. PLOS ONE. 2015;10(8):e0136133.

20. EV-TRACK Consortium, Van Deun J, Mestdagh P, Agostinis P, Akay Ö, Anand $S$, et al. EV-TRACK: transparent reporting and centralizing knowledge in extracellular vesicle research. Nat Methods. 2017;14(3):228-32.
21. Hayakawa K, Esposito E, Wang X, Terasaki Y, Liu Y, Xing C, et al. Transfer of mitochondria from astrocytes to neurons after stroke. Nature. 2016; 535(7613):551-5.

22. Hough KP, Trevor JL, Strenkowski JG, Wang Y, Chacko BK, Tousif S, et al. Exosomal transfer of mitochondria from airway myeloid-derived regulatory cells to T cells. Redox Biol. 2018;18:54-64. https://doi.org/10.1016/j.redox.201 8.06.009.

23. Jang SC, Crescitelli R, Cvjetkovic A, Belgrano V, Olofsson Bagge R, Sundfeldt $\mathrm{K}$, et al. Mitochondrial protein enriched extracellular vesicles discovered in human melanoma tissues can be detected in patient plasma. J Extracell Vesicles. 2019 Dec 1;8(1):1635420. https://doi.org/10.1 080/20013078.2019.1635420.

24. Guescini M, Genedani S, Stocchi V, Agnati LF. Astrocytes and Glioblastoma cells release exosomes carrying mtDNA. J Neural Transm Vienna Austria. 2010;117(1):1-4.

25. Sreedhar A, Aguilera-Aguirre L, Singh KK. Mitochondria in skin health, aging, and disease. Cell Death Dis. 2020;11(6):1-14

26. Daniele T, Hurbain I, Vago R, Casari G, Raposo G, Tacchetti C, et al. Mitochondria and Melanosomes establish physical contacts modulated by Mfn2 and involved in organelle biogenesis. Curr Biol. 2014 Feb;24(4):393403. https://doi.org/10.1016/j.cub.2014.01.007.

27. Lázaro-lbáñez E, Lässer C, Shelke GV, Crescitelli R, Jang SC, Cvjetkovic A, et al. DNA analysis of low- and high-density fractions defines heterogeneous subpopulations of small extracellular vesicles based on their DNA cargo and topology. J Extracell Vesicles. 2019;8(1):1656993. https://doi. org/10.1080/20013078.2019.1656993.

28. Vagner T, Spinelli C, Minciacchi VR, Balaj L, Zandian M, Conley A, et al. Large extracellular vesicles carry most of the tumour DNA circulating in prostate cancer patient plasma. J Extracell Vesicles. 2018;7(1):1505403. https://doi. org/10.1080/20013078.2018.1505403.

29. Takahashi A, Okada R, Nagao K, Kawamata Y, Hanyu A, Yoshimoto S, et al. Exosomes maintain cellular homeostasis by excreting harmful DNA from cells. Nat Commun. 2017;8:15287.

30. Sisquella X, Ofir-Birin Y, Pimentel MA, Cheng L, Abou Karam P, Sampaio NG, et al. Malaria parasite DNA-harbouring vesicles activate cytosolic immune sensors. Nat Commun. 2017:8(1):1985.

31. Wei Z, Batagov AO, Schinelli S, Wang J, Wang Y, El Fatimy R, et al. Coding and noncoding landscape of extracellular RNA released by human glioma stem cells. Nat Commun. 2017;8(1):1145.

32. Tosar JP, Segovia M, Castellano M, Gámbaro F, Akiyama Y, Fagúndez P, et al. Fragmentation of extracellular ribosomes and tRNAs hshapes the extracellular RNAome. Nucleic Acids Res. 2020;48(22):12874-88. https://doi. org/10.1093/nar/gkaa674.

33. Na CH, Sharma N, Madugundu AK, Chen R, Aksit MA, Rosson GD, et al. Integrated Transcriptomic and proteomic analysis of human Eccrine sweat glands identifies missing and novel proteins. Mol Cell Proteomics MCP. 2019;18(7):1382-95. https://doi.org/10.1074/mcp.RA118.001101.

34. Grice EA, Segre JA. The skin microbiome. Nat Rev Microbiol. 2011 Apr;9(4): 244-53. https://doi.org/10.1038/nrmicro2537.

35. Afshinnekoo E, Meydan C, Chowdhury S, Jaroudi D, Boyer C, Bernstein N, et al. Geospatial resolution of human and bacterial diversity with City-scale Metagenomics. Cell Syst. 2015 Jul 29;1(1):72-87. https://doi.org/10.1016/j. cels.2015.01.001.

36. Anderson JH, Tester DJ, Will ML, Ackerman MJ. Whole-exome molecular autopsy after exertion-related sudden unexplained death in the young. Circ Cardiovasc Genet. 2016 Jun;9(3):259-65. https://doi.org/10.1161/ CIRCGENETICS.115.001370.

37. Driedonks TAP, Mol S, de Bruin S, Peters A-L, Zhang X, Lindenbergh MFS, et al. Y-RNA subtype ratios in plasma extracellular vesicles are cell typespecific and are candidate biomarkers for inflammatory diseases. J Extracell Vesicles. 2020;9(1):1764213. https://doi.org/10.1080/20013078.2020.1764213.

38. Gulia C, Signore F, Gaffi M, Gigli S, Votino R, Nucciotti R, et al. Y RNA: an overview of their role as potential biomarkers and molecular targets in human cancers. Cancers (Basel). 2020;12(5):1238. https://doi.org/10.3390/ca ncers12051238.

39. Heintz-Buschart A, Yusuf D, Kaysen A, Etheridge A, Fritz JV, May P, et al. Small RNA profiling of low biomass samples: identification and removal of contaminants. BMC Biol. 2018 May 14;16(1):52. https://doi.org/10.1186/s1291 5-018-0522-7

40. Théry C, Witwer KW, Aikawa E, Alcaraz MJ, Anderson JD, Andriantsitohaina $\mathrm{R}$, et al. Minimal information for studies of 
extracellular vesicles 2018 (MISEV2018): a position statement of the International Society for Extracellular Vesicles and update of the MISE V2014 guidelines. J Extracell Vesicles. 2018;7(1):1535750. https://doi.org/1 0.1080/20013078.2018.1535750.

41. Guescini M, Guidolin D, Vallorani L, Casadei L, Gioacchini AM, Tibollo P, et al. C2C12 myoblasts release micro-vesicles containing mtDNA and proteins involved in signal transduction. Exp Cell Res. 2010 Jul;316(12):1977-84. https://doi.org/10.1016/j.yexcr.2010.04.006.

42. Wingett SW, Andrews S. FastQ Screen: A tool for multi-genome mapping and quality control. F1000Research. 2018;7:1338.

43. Zhang J, Kobert K, Flouri T, Stamatakis A. PEAR: a fast and accurate Illumina paired-end reAd mergeR. Bioinforma Oxf Engl. 2014;30(5):614-20. https:// doi.org/10.1093/bioinformatics/btt593.

44. Li H, Durbin R. Fast and accurate short read alignment with burrowswheeler transform. Bioinforma Oxf Engl. 2009;25(14):1754-60. https://doi. org/10.1093/bioinformatics/btp324.

45. Bolger AM, Lohse $\mathrm{M}$, Usadel B. Trimmomatic: a flexible trimmer for Illumina sequence data. Bioinformatics. 2014 Aug 1;30(15):2114-20. https://doi.org/1 0.1093/bioinformatics/btu170.

46. Langmead B, Trapnell C, Pop M, Salzberg SL. Ultrafast and memory-efficient alignment of short DNA sequences to the human genome. Genome Biol. 2009;10(3):R25. https://doi.org/10.1186/gb-2009-10-3-r25.

47. Chan PP, Lowe TM. GtRNAdb: a database of transfer RNA genes detected in genomic sequence. Nucleic Acids Res. 2009;37(Database issue):D93-7. https://doi.org/10.1093/nar/gkn787.

48. Trapnell C, Williams BA, Pertea G, Mortazavi A, Kwan G, van Baren MJ, et al. Transcript assembly and quantification by RNA-Seq reveals unannotated transcripts and isoform switching during cell differentiation. Nat Biotechnol. 2010 May;28(5):511-5. https://doi.org/10.1038/nbt.1621.

49. Griffiths-Jones S. miRBase: microRNA sequences, targets and gene nomenclature. Nucleic Acids Res. 2006;34(90001):D140-4. https://doi.org/1 0.1093/nar/gkj112.

50. Kozomara A, Birgaoanu M, Griffiths-Jones S. miRBase: from microRNA sequences to function. Nucleic Acids Res. 2019 Jan 8;47(D1):D155-62. https://doi.org/10.1093/nar/gky1141

51. Wang J, Zhang P, Lu Y, Li Y, Zheng Y, Kan Y, et al. piRBase: a comprehensive database of piRNA sequences. Nucleic Acids Res. 2019 Jan 8:47(D1):D17580. https://doi.org/10.1093/nar/gky1043.

52. Liao Y, Smyth GK, Shi W. featureCounts: an efficient general purpose program for assigning sequence reads to genomic features. Bioinforma Oxf Engl. 2014;30(7):923-30. https://doi.org/10.1093/bioinformatics/btt656.

53. Dobin A, Davis CA, Schlesinger F, Drenkow J, Zaleski C, Jha S, et al. STAR: ultrafast universal RNA-seq aligner. Bioinformatics. 2013 Jan;29(1):15-21. https://doi.org/10.1093/bioinformatics/bts635.

54. Kallio MA, Tuimala JT, Hupponen T, Klemelä P, Gentile M, Scheinin I, et al. Chipster: user-friendly analysis software for microarray and other highthroughput data. BMC Genomics. 2011 Oct 14;12(1):507. https://doi.org/1 $0.1186 / 1471-2164-12-507$

55. Li D, Luo R, Liu C-M, Leung C-M, Ting H-F, Sadakane K, et al. MEGAHIT v1.0: A fast and scalable metagenome assembler driven by advanced methodologies and community practices. Methods San Diego Calif. 2016; 102:3-11.

56. Buchfink B, Xie C, Huson DH. Fast and sensitive protein alignment using DIAMOND. Nat Methods. 2015 Jan;12(1):59-60. https://doi.org/10.1038/ nmeth.3176.

57. Wood DE, Salzberg SL. Kraken: ultrafast metagenomic sequence classification using exact alignments. Genome Biol. 2014 Mar 3;15(3):R46. https://doi.org/10.1186/gb-2014-15-3-r46.

58. Ondov BD, Bergman NH, Phillippy AM. Interactive metagenomic visualization in a web browser. BMC Bioinformatics. 2011 Sep 30;12(1):385. https://doi.org/10.1186/1471-2105-12-385.

59. Ashburner M, Ball CA, Blake JA, Botstein D, Butler H, Cherry JM, et al. Gene ontology: tool for the unification of biology. Nat Genet. 2000 May;25(1):259. https://doi.org/10.1038/75556.

60. Supek F, Bošnjak M, Škunca N, Šmuc T. REVIGO Summarizes and Visualizes Long Lists of Gene Ontology Terms. Gibas C, editor. PLoS ONE. 2011;6(7): e21800.

\section{Publisher's Note}

Springer Nature remains neutral with regard to jurisdictional claims in published maps and institutional affiliations.

Ready to submit your research? Choose BMC and benefit from:

- fast, convenient online submission

- thorough peer review by experienced researchers in your field

- rapid publication on acceptance

- support for research data, including large and complex data types

- gold Open Access which fosters wider collaboration and increased citations

- maximum visibility for your research: over $100 \mathrm{M}$ website views per year

At BMC, research is always in progress.

Learn more biomedcentral.com/submissions 